\title{
New measurements of D/H on Mars using EXES aboard SOFIA
}

\author{
T. Encrenaz ${ }^{1}$, C. DeWitt ${ }^{2}$, M. J. Richter ${ }^{2}$, T. K. Greathouse ${ }^{3}$, T. Fouchet ${ }^{1}$, F. Montmessin ${ }^{4}$, F. Lefèvre ${ }^{4}$, B. Bézard ${ }^{1}$, \\ S. K. Atreya ${ }^{5}$, S. Aoki ${ }^{6}$, and H. Sagawa ${ }^{7}$ \\ ${ }^{1}$ LESIA, Observatoire de Paris, PSL University, CNRS, UPMC, Univ. Denis Diderot, 92195 Meudon, France \\ 2 Dept. of Physics, University of California Davis, CA 95616, USA \\ ${ }^{3}$ SwRI, Div. 15, San Antonio, TX 78228, USA \\ ${ }^{4}$ LATMOS, IPSL, 75252 Paris Cedex 05, France \\ 5 Dept. of Climate and Space Sciences, University of Michigan, Ann Arbor, MI 48109-2143, USA \\ ${ }^{6}$ Belgium Institute for Space Aeronomy (BIRA-IASB), 1180 Brussels, and Fonds National de la Recherche Scientifique, \\ 1000 Brussels, Belgium \\ ${ }^{7}$ Kyoto-Sangio University, Kyoto 603-8555, Japan
}

Received 27 November 2017 / Accepted 21 January 2018

\begin{abstract}
The global D/H ratio on Mars is an important measurement for understanding the past history of water on Mars; locally, through condensation and sublimation processes, it is a possible tracer of the sources and sinks of water vapor on Mars. Measuring D/H as a function of longitude, latitude and season is necessary for determining the present averaged value of D/H on Mars. Following an earlier measurement in April 2014, we used the Echelon Cross Echelle Spectrograph (EXES) instrument on board the Stratospheric Observatory for Infrared Astronomy (SOFIA) facility to map D/H on Mars on two occasions, on March 24, $2016\left(\mathrm{~L} s=127^{\circ}\right)$, and January $24,2017\left(\mathrm{~L} s=304^{\circ}\right)$, by measuring simultaneously the abundances of $\mathrm{H}_{2} \mathrm{O}$ and $\mathrm{HDO}$ in the $1383-1391 \mathrm{~cm}^{-1} \mathrm{range}(7.2 \mu \mathrm{m})$. The D/H disk-integrated values are $4.0(+0.8,-0.6) \times$ Vienna Standard Mean Ocean Water $($ VSMOW) and 4.5 $(+0.7,-0.6) \times$ VSMOW, respectively, in agreement with our earlier result. The main result of this study is that there is no evidence of strong local variations in the $\mathrm{D} / \mathrm{H}$ ratio nor for seasonal variations in the global $\mathrm{D} / \mathrm{H}$ ratio between northern summer and southern summer.
\end{abstract}

Key words. planets and satellites: atmospheres - planets and satellites: individual: Mars

\section{Introduction}

Measuring the $\mathrm{D} / \mathrm{H}$ ratio in the Martian atmosphere is important for estimating the abundance of the early water reservoir on Mars. Indeed, the main mechanism responsible for the deuterium enrichment in the Martian atmosphere is expected to be fractionation through differential escape rates of the $\mathrm{D}$ and $\mathrm{H}$ atoms, the post-decomposition products of the $\mathrm{HDO}$ and $\mathrm{H}_{2} \mathrm{O}$ molecules (Owen et al. 1988). The disk-integrated estimate of the $\mathrm{D} / \mathrm{H}$ ratio must be compared with its value in the past, measured in the most ancient SNC meteorites and/or in clays at the Martian surface (Greenwood et al. 2008; Usui et al. 2012; Mahaffy et al. 2015). For a precise measurement of the present D/H ratio on Mars and in order to avoid any possible seasonal variation, $\mathrm{D} / \mathrm{H}$ should be, as much as possible, integrated over an entire Martian year.

The HDO molecule was first detected on Mars by Owen et al. (1988) who inferred, from near-infrared ground-based observations, a D/H ratio of $6 \pm 3$ times the terrestrial value (the Vienna Standard Mean Ocean Water, VSMOW, is equal to $\left.1.556 \times 10^{-4}\right)$. Many observations have been performed since 1988 (Bjoraker et al. 1989; Krasnopolsky et al. 1997; Encrenaz et al. 2001), all consistent with the first detection. More recently, attempts to map $\mathrm{D} / \mathrm{H}$ on Mars as a function of latitude and season have been performed by Novak et al. (2011), Villanueva et al. (2015), Krasnopolsky (2015), Aoki et al. (2015) and Encrenaz et al. (2016).

In addition to its cosmogonical interest, the measurement of $\mathrm{D} / \mathrm{H}$ in water on Mars as a function of altitude, location, and season can bring important constraints on the mechanisms responsible for the sources and sinks of water vapor on the modern day Martian surface and atmosphere. The main mechanism is the vapor pressure isotope effect (VPIE), a fractionation mechanism associated with condensation/sublimation processes. At thermodynamical equilibrium, the $\mathrm{HDO} / \mathrm{H}_{2} \mathrm{O}$ ratio in ice, compared with that in the gas phase, is known to be a decreasing function of temperature (Merlivat \& Nief 1967). The latitudinal gradient of $\mathrm{D} / \mathrm{H}$ is constrained by the sublimation of the northern polar cap and the condensation in the southern polar regions. Thus, due to the general atmospheric circulation, the $\mathrm{D} / \mathrm{H}$ ratio in water vapor is expected to be highest at the north pole at northern summer solstice, and to increase with the water vapor content and with the temperature, as predicted by Fouchet \& Lellouch (2000) and Montmessin et al. (2005). However, Villanueva et al. (2015) have reported in some cases strong variations in D/H over the Martian disk, larger than expected by the models. Mapping $\mathrm{D} / \mathrm{H}$ for different latitude and longitude ranges, and for different seasons, can allow us to test this model.

In April 2014, we used the Echelon Cross Echelle Spectrograph (EXES) instrument on board the Stratospheric Observatory for Infrared Astronomy (SOFIA) facility in order to observe $\mathrm{H}_{2} \mathrm{O}, \mathrm{HDO}$, and $\mathrm{CO}_{2}$ transitions in the thermal infrared $(7 \mu \mathrm{m})$. The $\mathrm{D} / \mathrm{H}$ ratio was directly derived from the HDO and $\mathrm{H}_{2} \mathrm{O}$ line depth ratios. The diameter of Mars was 15 arcsec, allowing us to build a map of $\mathrm{D} / \mathrm{H}$ in spite of the poor seeing experienced by the SOFIA telescope ( 3 arcsec). Our diskaveraged $\mathrm{D} / \mathrm{H}$ mixing ratio was $4.4(+1.1,-0.6) \times \mathrm{VSMOW}$, in global agreement with previous observations and model predictions. 
Table 1. Summary of EXES observations of Mars.

\begin{tabular}{lllllllll}
\hline \hline $\begin{array}{l}\text { Date } \\
\text { of obs. }\end{array}$ & UT & Ls & $\begin{array}{l}\text { Mars } \\
\text { diameter } \\
(\operatorname{arcsec})\end{array}$ & $\begin{array}{l}\text { SEP W-long } \\
\left({ }^{\circ}\right)\end{array}$ & $\begin{array}{l}\text { SEP-lat } \\
\left({ }^{\circ}\right)\end{array}$ & $\begin{array}{l}\text { Doppler } \\
\text { velocity } \\
\left(\mathrm{km} \mathrm{s}^{-1}\right)\end{array}$ & $\begin{array}{l}\text { Doppler } \\
\text { shift } \\
\left(\mathrm{cm}^{-1}\right)\end{array}$ & $\begin{array}{l}\text { Aircraft } \\
\text { altitude } \\
(\mathrm{km})\end{array}$ \\
\hline 2014 April 8 & $05: 00-05: 30$ & 113 & 15 & 160 & 25 & -2.7 & +0.0125 & 11.6 \\
2016 March 24 & $12: 20-12: 31$ & 127 & 11 & 167 & -3 & -16.2 & +0.075 & 13.7 \\
2017 January 24 & $00: 50-01: 30$ & 304 & 5.2 & 357 & -25 & +11.7 & -0.053 & 11.9 \\
\hline
\end{tabular}

Notes. SEP = sub-Earth point.

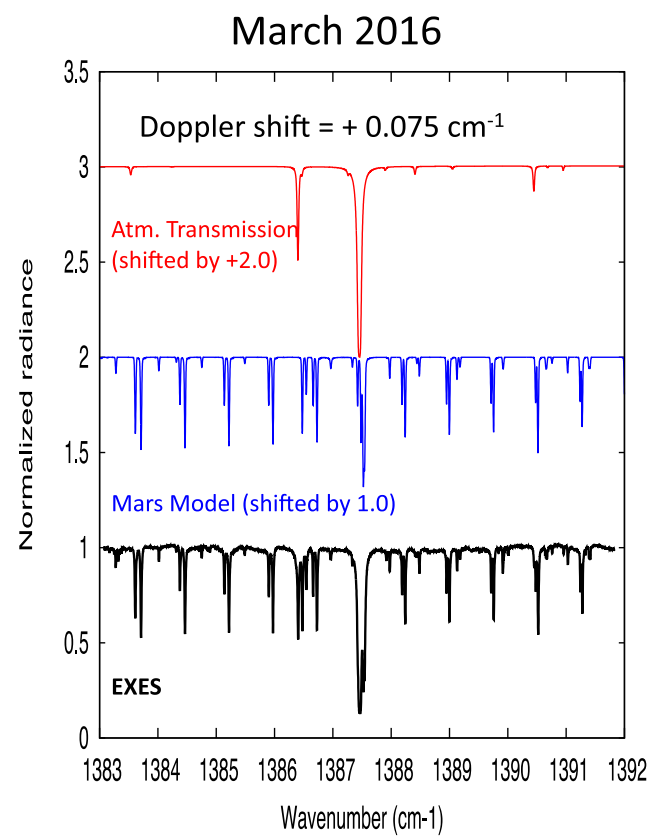

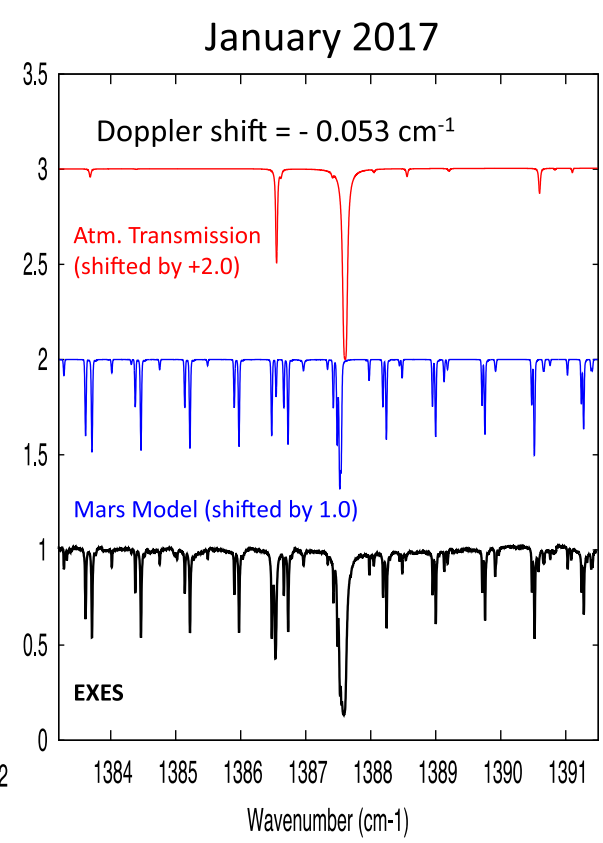

Fig. 1. Thick black line: EXES spectrum of Mars between 1383.5 and $1391.5 \mathrm{~cm}^{-1}$, integrated over the Martian disk (normalized radiance). Blue line: nominal synthetic model of the Martian atmosphere (shifted by +1.0 ). Red: nominal model of the terrestrial opacity, for an altitude of $14 \mathrm{~km}$, computed with the EXES model, shifted by +2.0 . Left: March 24, 2016, data (Doppler shift: $\left.+0.075 \mathrm{~cm}^{-1}\right)$; right: January 24, 2017, data (Doppler shift: $-0.053 \mathrm{~cm}^{-1}$ ).
We continued our observing campaign with EXES on board SOFIA in order to map $\mathrm{D} / \mathrm{H}$ on Mars for different longitude ranges and different seasons. A second run was obtained in March $2016\left(\mathrm{Ls}=127^{\circ}\right)$, when the diameter of Mars was 11 arcsec. A third run was obtained in January 2017 when the Martian season was opposite $\left(\mathrm{L} s=304^{\circ}\right)$. As the diameter of Mars was only 5.2 arcsec, we did not build a map and we only obtained latitudinal scans of the $\mathrm{D} / \mathrm{H}$ ratio.

In this paper, we present the analysis of the EXES spectra of Mars recorded during the two flights of EXES on March 24, 2016, and January 24, 2017. Section 2 describes the observations, the radiative transfer model used in our analysis, and the retrieval of the terrestrial opacity. The results of the two runs are presented in Sect. 3 and discussed in Sect. 4.

\section{Observations and modeling}

\subsection{Observations}

The Echelon Cross Echelle Spectrograph (Richter et al. 2010) was derived from the Texas Echelon Cross Echelle Spectrograph (TEXES) instrument in operation at the NASA InfraRed Telescope Facility (Lacy et al. 2002). EXES operates between 4.5 and $28.3 \mu \mathrm{m}\left(350-2220 \mathrm{~cm}^{-1}\right)$ in three different modes: high resolution $(R=50000-100000)$, medium resolution ( $R=5000-20000)$, and low resolution $(R=1000-3000)$. We used the high resolution mode and we selected the 1383 $1391 \mathrm{~cm}^{-1}$ interval (slightly shifted with respect to our first observation of May 2014), in order to optimize the number of weak and strong transitions of $\mathrm{H}_{2} \mathrm{O}, \mathrm{HDO}$, and $\mathrm{CO}_{2}$. At $1387 \mathrm{~cm}^{-1}$, the spectral resolution is better than $0.028 \mathrm{~cm}^{-1}$ ( $R$ higher than 50000 ).

Table 1 summarizes the EXES observations of 2014, 2016, and 2017. The slit length was 11.8 arcsec and its width was 1.44 arcsec. In March 2016, we used the same strategy as in the case of our 2014 observations. We scanned the slit across the planet with 35 steps of 0.19 arcsec east and 0.69 arcsec north, starting from an offset position of -2.12 arcsec east and -14.56 arcsec north with respect to the planet center. In view of the planet's size, a single scan was sufficient to cover the whole disk. Two successive scans were recorded, the first between UT 12:20:41.12 and UT 12:25:25.0 and the second between UT 12:25:44.7 and 12:30:27.3. In January 2017, due to the small size of the planet and the poor seeing of the SOFIA telescope, we registered a series of scans close to the center of the planet, and we retrieved $\mathrm{D} / \mathrm{H}$ as a function of latitude. The geometry of the 2017 observations is described below (Sect. 3.2).

The EXES observations of March 2016 and January 2017 show a significant advantage over the previous observation. Indeed, the Doppler shift is higher than the spectral resolution by a factor of 2-3 or more (depending on the actual resolving power, as will be discussed below), so that the Martian water lines $\left(\mathrm{H}_{2} \mathrm{O}\right.$ and HDO) are separated from the terrestrial lines, which was not the case in April 2014; the correction of the terrestrial opacity is thus much easier than in the case of our previous run (the counterpart is of course that Mars is smaller). 


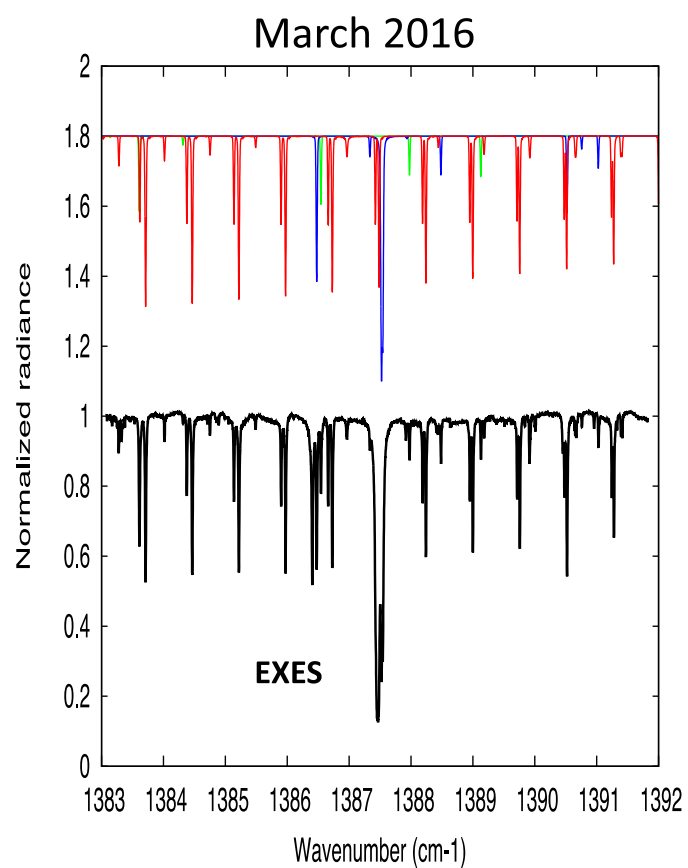

Figure 1 shows the disk-integrated spectrum of Mars between 1383 and $1391 \mathrm{~cm}^{-1}$, for both the March 2016 and the January 2017 runs. A nominal synthetic spectrum of Mars including $\mathrm{CO}_{2}, \mathrm{H}_{2} \mathrm{O}$, and $\mathrm{HDO}$ is shown for comparison, with a standard spectrum of the terrestrial atmospheric transmission, calculated for an altitude of $14 \mathrm{~km}$. Because the Doppler shift has an opposite sign for both runs, the terrestrial absorption lines are shifted in opposite directions versus the Martian spectrum. As a result, the shape of the EXES spectrum is different in the two cases, especially in the $1386-1388 \mathrm{~cm}^{-1}$ range where strong telluric features appear.

Figure 2 shows the two EXES spectra of March 2016 and January 2017, compared to our nominal model of Mars showing contributions by $\mathrm{CO}_{2}, \mathrm{H}_{2} \mathrm{O}$, and $\mathrm{HDO}$. It can be seen that the spectrum of Mars is dominated by a regular series of $\mathrm{CO}_{2}$ doublets. Between 1386 and $1388 \mathrm{~cm}^{-1}$, two strong terrestrial $\mathrm{H}_{2} \mathrm{O}$ absorption features, centered around 1386.5 and $1387.5 \mathrm{~cm}^{-1}$, are superimposed on the Mars spectrum and dominate the EXES spectrum. In contrast, between 1387.8 and $1391.5 \mathrm{~cm}^{-1}$, weak isolated lines of $\mathrm{H}_{2} \mathrm{O}$ and $\mathrm{HDO}$ appear in the Mars spectrum, well separated from their terrestrial counterparts. We thus use the $1386-1388 \mathrm{~cm}^{-1}$ range to model the terrestrial opacity, and we use it to correct the EXES spectrum over the whole spectral range. Then, we select the $1387.8-1391.4 \mathrm{~cm}^{-1}$ range for our analysis of the $\mathrm{H}_{2} \mathrm{O}$ and $\mathrm{HDO}$ mixing ratios.

\subsection{Atmospheric modeling}

To model the Martian synthetic spectrum, we used the radiative transfer code developed for our analysis of the TEXES data of Mars (Encrenaz et al. 2004, 2015), and also used for the analysis of our EXES data of April 2014 (Encrenaz et al. 2016). Spectroscopic data were extracted from the GEISA molecular database (Jacquinet-Husson et al. 2008). As a first step, for both datasets, we used the disk-integrated spectra of Mars (for a maximum signal-to-noise ratio) in order to estimate the contribution of the terrestrial atmospheric opacity. In the case of the March 2016 data, we used a surface temperature of $255 \mathrm{~K}$, a surface pressure of 6.0 mbar, and temperatures of $230,200,170$, and $140 \mathrm{~K}$ at altitude levels of $0,10,20$, and $40 \mathrm{~km}$ respectively, with an
January 2017

Fig. 2. Thick black line: EXES spectrum of Mars between 1383.5 and $1391.5 \mathrm{~cm}^{-1}$, integrated over the Martian disk (normalized radiance). Synthetic models of the Martian atmosphere: contributions due to $\mathrm{CO}_{2}$ (red), $\mathrm{H}_{2} \mathrm{O}$ (300 ppmv, blue), HDO (467 ppbv, green). Left: March 24, 2016, data (Doppler shift: $\left.+0.075 \mathrm{~cm}^{-1}\right)$; right: January 24, 2017, data (Doppler shift: $\left.-0.053 \mathrm{~cm}^{-1}\right)$. isothermal profile above $40 \mathrm{~km}$. This profile, close to that predicted by the European Mars Climate Database (EMCD; Forget et al. 1999), is the same as the one we used for our data of April 2014, which corresponded to a similar season and the same longitude range. In the case of the January 2017 data, also in agreement with the EMCD, we used a surface temperature of $250 \mathrm{~K}$, a surface pressure of $5.5 \mathrm{mbar}$, and temperatures of $230,220,195$, and $145 \mathrm{~K}$ at altitude levels of $0,10,20$, and $40 \mathrm{~km}$ respectively, with an isothermal profile above $40 \mathrm{~km}$. As in our previous analysis, for both datasets, we used the $\mathrm{CO}_{2}$ lines to determine the spectral resolution of our data. The best fit of the line width was obtained for a Gaussian profile with a FWHM of $0.022 \mathrm{~cm}^{-1}(R=63000)$ for the March 2016 data, and $0.020 \mathrm{~cm}^{-1}(R=69000)$ for the January 2017 data (Fig. 3). As in our previous analysis, we note that this profile does not perfectly fit the EXES lines, which show broader wings than the Gaussian profile, while the central core tends to be narrower. As shown in our earlier analysis (Encrenaz et al. 2016), the sinc ${ }^{2}$ function is very close to the Gaussian curve and does not improve the fit with our data. We adopted these Gaussian profiles and these resolving powers as a compromise to minimize the discrepancies between the data and the model. The resolving powers adopted in this study are actually slightly degraded with respect to the theoretical instrumental function of the EXES instrument. Part of the explanation comes from the fact that in order to get the best signal-to-noise ratio for the $\mathrm{H}_{2} \mathrm{O}$ and $\mathrm{HDO}$ retrievals, we are using disk-integrated spectra for which the FWHM is slightly broader than for spectra corresponding to single pixels. This effect might be due to a very small shift of the wavenumber scale as the slit moves over the planet.

As in our previous analyses, we directly determine the mixing ratios of $\mathrm{H}_{2} \mathrm{O}$ and $\mathrm{HDO}$ with respect to $\mathrm{CO}_{2}$ by making the ratio of the $\mathrm{H}_{2} \mathrm{O}$ or $\mathrm{HDO}$ line depth divided by the $\mathrm{CO}_{2}$ line depth. In our previous analyses of the TEXES spectra of Mars (Encrenaz et al. 2015), we showed that the mixing ratio of two atmospheric species can be directly estimated from the ratio of their line depths provided that the lines are weak, with line depths less than about $10 \%$. The validity of this method also requires that the two species be homogeneously mixed. We applied this method for the analysis of the EXES data 
Table 2. Spectroscopic parameters of the transitions used for the $\mathrm{HDO}$ and $\mathrm{CO}_{2}$ mapping and for the spectral fits ( $n$ is the temperature dependence factor of the broadening coefficient).

\begin{tabular}{llllllll}
\hline \hline Molecule & $\begin{array}{l}\text { Wavenumber } \\
\left(\mathrm{cm}^{-1}\right)\end{array}$ & $Q N$ (band) & $Q N$ (line) & $\begin{array}{l}S \\
\left(\mathrm{~cm} \mathrm{~mol}^{-1}\right)\end{array}$ & $\begin{array}{l}E \\
\left(\mathrm{~cm}^{-1}\right)\end{array}$ & $\begin{array}{l}\text { Broad. coef. } \\
\left(\mathrm{cm}^{-1} \mathrm{~atm}^{-1}\right)\end{array}$ & $n$ \\
\hline $\mathrm{H}_{2} \mathrm{O}$ & 1388.484 & 010000 & $615-642$ & $1.68 \times 10^{-22}$ & 757.8 & 0.105 & 0.46 \\
$\mathrm{H} 2 \mathrm{O}$ & 1391.026 & 010000 & $11011-11110$ & $6.44 \times 10^{-22}$ & 1524.8 & 0.105 & 0.46 \\
\hline $\mathrm{HDO}$ & 1387.976 & 010000 & $000-101$ & $7.10 \times 10^{-24}$ & 15.5 & 0.206 & 0.69 \\
$\mathrm{HDO}$ & 1389.127 & 010000 & $111-202$ & $5.29 \times 10^{-24}$ & 46.2 & 0.192 & 0.67 \\
$\mathrm{HDO}$ & 1389.132 & 010000 & $313-312$ & $2.53 \times 10^{-24}$ & 116.5 & 0.192 & 0.67 \\
\hline $\mathrm{CO}_{2}$ & 1386.964 & 1110101101 & Q1F & $4.69 \times 10^{-27}$ & 663.1 & 0.119 & 0.75 \\
$\mathrm{CO}_{2}$ & 1386.967 & 1110101101 & Q1E & $4.69 \times 10^{-27}$ & 663.1 & 0.119 & 0.75 \\
$\mathrm{CO}_{2}$ & 1389.177 & 1110101101 & R2E & $8.29 \times 10^{-27}$ & 664.6 & 0.102 & 0.68 \\
$\mathrm{CO}_{2}$ & 1389.184 & 1110101101 & R2F & $8.29 \times 10^{-27}$ & 664.6 & 0.102 & 0.68 \\
$\mathrm{CO}_{2}$ & 1389.915 & 1110101101 & R3E & $1.15 \times 10^{-26}$ & 666.8 & 0.119 & 0.75 \\
$\mathrm{CO}_{2}$ & 1389.925 & 1110101101 & R3F & $1.15 \times 10^{-26}$ & 666.8 & 0.119 & 0.75 \\
\hline
\end{tabular}

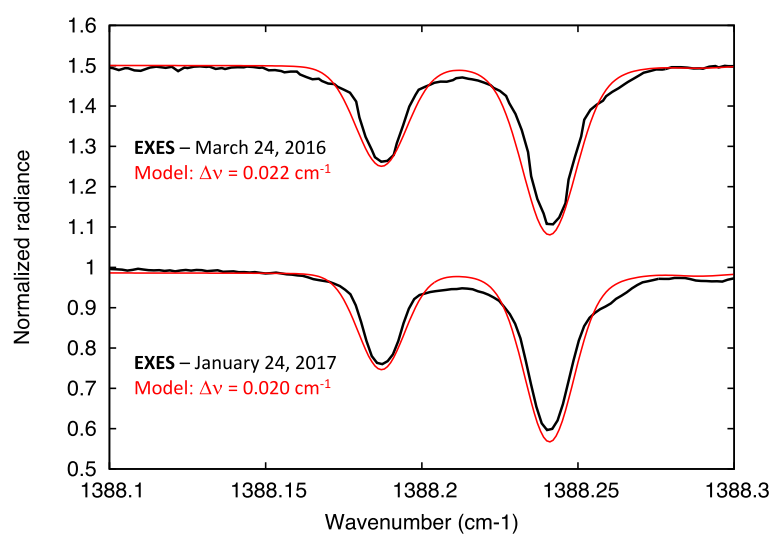

Fig. 3. Top (shifted by +0.5): EXES spectrum of Mars between 1388.05 and $1388.35 \mathrm{~cm}^{-1}$, integrated over the Martian disk (thick black line), recorded with EXES on March 24, 2016 ( Ls $=127^{\circ}$, normalized radiance). The synthetic model of the Martian atmosphere with the $\mathrm{CO}_{2}$ contribution (red curve) corresponds to a Gaussian profile with a FWHM of $0.022 \mathrm{~cm}^{-1}$. Bottom: EXES spectrum recorded on January 24, 2017, over the slit and summed over the six scans. The synthetic model corresponds to a Gaussian profile with a FWHM of $0.020 \mathrm{~cm}^{-1}$.

obtained in May 2014 (Encrenaz et al. 2016). However, we must be aware of the limitations of this method. First, if the water is concentrated just above the surface, which may occur in particular near aphelion, $\mathrm{H}_{2} \mathrm{O}$ and $\mathrm{HDO}$ may not be homogeneously mixed. Second, when the airmass is higher than 5, the departure from linearity may exceed $10 \%$ (Encrenaz et al. 2015). This means that results obtained near the limb should be considered with caution.

In the case of the $\mathrm{D} / \mathrm{H}$ retrieval, the determination of the $\mathrm{H}_{2} \mathrm{O}$ and $\mathrm{HDO}$ volume mixing ratios, using the $\mathrm{H}_{2} \mathrm{O} / \mathrm{CO}_{2}$ and $\mathrm{HDO} / \mathrm{CO}_{2}$ line depth ratios, is made to check the consistency of our results with respect to Global Climate Models and other observations. To retrieve the $\mathrm{D} / \mathrm{H}$ ratio, we simply use the $\mathrm{HDO} / \mathrm{H}_{2} \mathrm{O}$ line depth ratio (taking into account that $\left[\mathrm{HDO} / \mathrm{H}_{2} \mathrm{O}\right]$ $=2 \times \mathrm{D} / \mathrm{H})$. The advantage of using the $\mathrm{HDO} / \mathrm{H}_{2} \mathrm{O}$ line depth ratio directly is that no assumption is required on the precise thermal structure of the atmosphere since there is no need to use $\mathrm{CO}_{2}$ transitions (Encrenaz et al. 2016). Table 2 describes the spectroscopic parameters of the transitions used in our calculations, for the March 2016 and January 2017 runs. It can be noted that some of the $\mathrm{HDO}$ and $\mathrm{CO}_{2}$ lines are actually very close doublets (their separation is within the spectral resolution of the EXES data).

\subsection{Retrieval of the terrestrial atmospheric transmission}

In order to obtain a precise correction of the terrestrial contribution in the EXES spectra over the whole spectral range, we model the terrestrial atmosphere and we adjust the temperature, pressure, and water content in the Earth's atmosphere to obtain the best fit of the strong terrestrial absorption at $1386-1388 \mathrm{~cm}^{-1}$. This method can be used because in this spectral range the contribution of the Martian spectrum is very minor compared to the terrestrial absorption.

Two main factors determine the shape of the terrestrial atmospheric transmission in the $\mathrm{H}_{2} \mathrm{O}$ and HDO absorptions: the pressure level above which the calculation is made, and the water vertical distribution above this level. We calculated a grid of spectra for different values of these parameters, and we multiplied these transmission curves with our nominal synthetic model of Mars to obtain the best fit of the disk-integrated EXES spectrum of Mars. The best-fit transmission curve (Fig. 4) corresponds to an altitude level of $14 \mathrm{~km}$ (consistent with the flight altitude of SOFIA in March 2016) and a pressure of 0.11 bar at this level. The water mixing ratio ranges from $3 \times 10^{-5}$ at the first level to $5 \times 10^{-6} 5 \mathrm{~km}$ above this level, in agreement with standard models of the terrestrial atmosphere (Jimenez et al. 2013). In order to fit the observed spectrum at the center of the $1387.5 \mathrm{~cm}^{-1} \mathrm{H}_{2} \mathrm{O}$ band where the terrestrial transmission is expected to be null, we removed the offset due presumably to scattered light or to incomplete sky subtraction (the same effect was observed in our April 2014 observation). It can be seen that our retrieved terrestrial transmission curve leads to a good overall agreement with the EXES disk-integrated spectrum for the March 2016 and January 2017 runs.

\section{Results}

\subsection{The March 2016 observations}

We first used the disk-integrated EXES spectrum of Mars to retrieve mean values of the $\mathrm{H}_{2} \mathrm{O}$ and $\mathrm{HDO}$ volume mixing 
March 2016

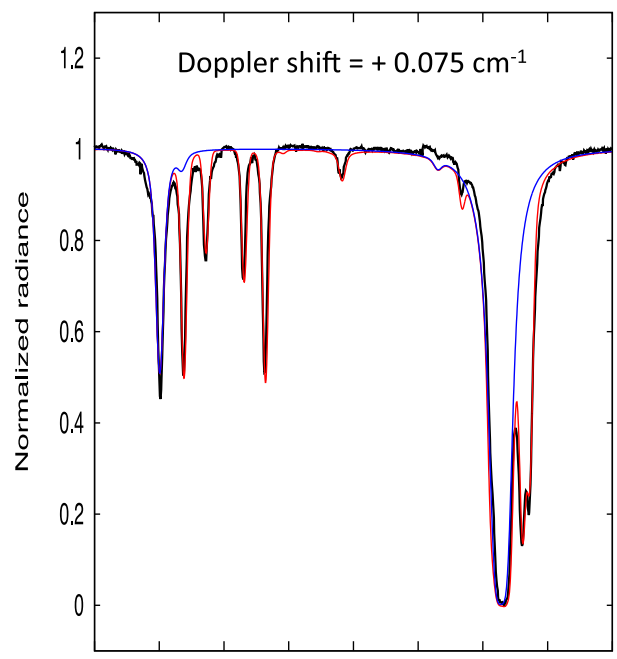

1386.2 $1386.41386 .61386 .8 \quad 1387 \quad 1387.21387 .41387 .61387 .8$

Wavenumber $(\mathrm{cm}-1)$
January 2017

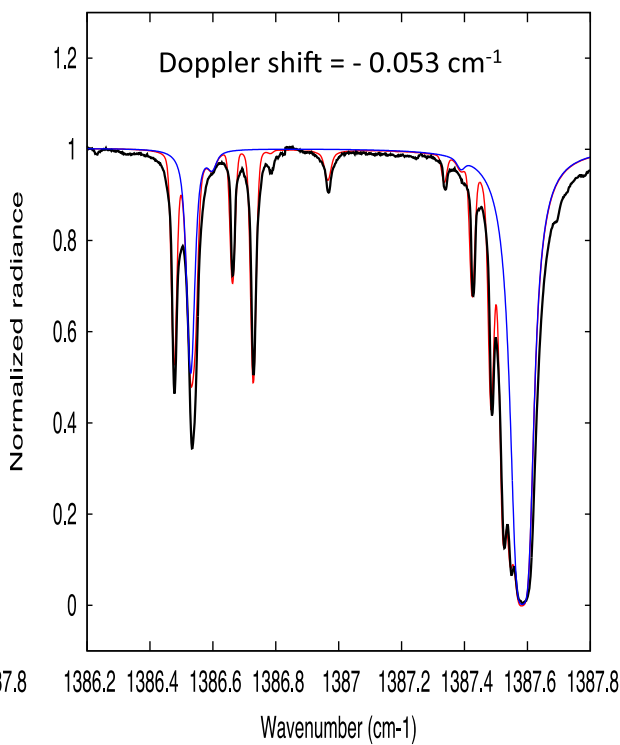

Fig. 4. Thick black line: EXES diskintegrated spectrum of Mars. Blue: bestfit atmospheric transmission over an altitude of $14 \mathrm{~km}$. Red: best-fit model of Mars, multiplied by the terrestrial transmission, for comparison with the EXES spectrum. Left: March 24, 2016, data; right: January 24, 2017, data. It can be seen that the terrestrial transmission curve is the same for both runs.

EXES- March 24, $2016-\mathrm{Ls}=127^{\circ}$

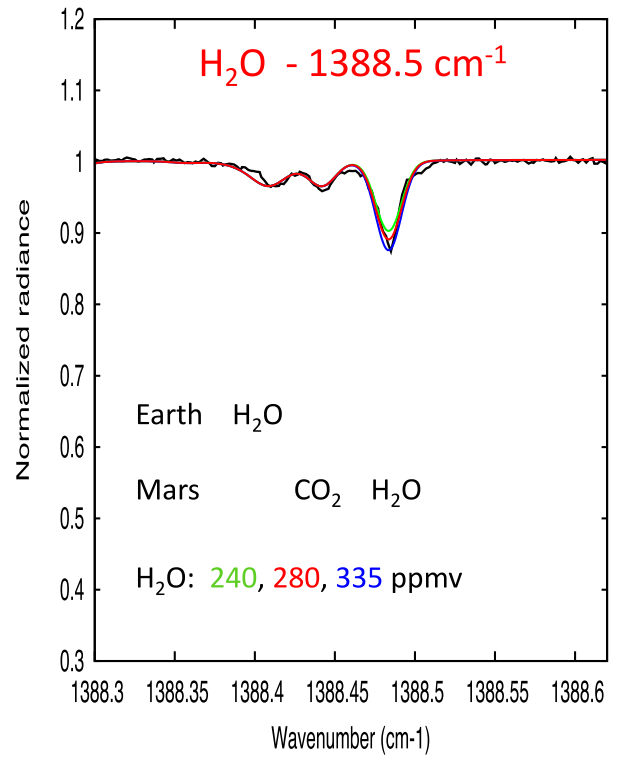

Fig. 5. Thick black line: the EXES diskintegrated spectrum of Mars recorded on March 24, 2016 in two $\mathrm{H}_{2} \mathrm{O}$ transitions. Left: the $1388.5 \mathrm{~cm}^{-1}$ transition; right: the $1391.0 \mathrm{~cm}^{-1}$ transition. Models: $\mathrm{H}_{2} \mathrm{O}$ $=240$ ppmv (green), 280 ppbv (red, best fit), 335 ppbv (blue). ratios. Figure 5 shows two $\mathrm{H}_{2} \mathrm{O}$ transitions, at 1388.484 and $1391.026 \mathrm{~cm}^{-1}$, respectively. Figure 6 shows two HDO transitions, at 1387.976 and $1389.13 \mathrm{~cm}^{-1}$, respectively. In both cases, it can be seen that the EXES disk-integrated spectrum is bracketed by the two extreme models shown in the figures $\left(\mathrm{H}_{2} \mathrm{O}=\right.$ 240-335 ppmv, HDO = 280-420 ppbv). Considering that these extreme values correspond to a peak-to-peak uncertainty of $3 \sigma$, we derive from Fig. 5 a best-fit $\mathrm{H}_{2} \mathrm{O}$ mean volume mixing ratio of $280(+37,-27)$ ppmv, and we infer from Fig. 6 a best-fit mean HDO mixing ratio of $350( \pm 47)$ ppbv. As pointed out above, these weak transitions of $\mathrm{H}_{2} \mathrm{O}$ and $\mathrm{HDO}$ are well separated from their terrestrial counterparts, so - in contrast with the April 2014 analysis - there is no uncertainty coming from the correction of the terrestrial atmospheric transmission. Taking into account that two lines of each species are used, we derive a disk-integrated $\mathrm{D} / \mathrm{H}$ mixing ratio of $4.0(+0.8,-0.6) \times \mathrm{VSMOW}$, in agreement with our result of April 2014.
Figure 7 shows a map of the continuum radiance of Mars at $1388.42 \mathrm{~cm}^{-1}$ and a map of the line depth of a weak $\mathrm{CO}_{2}$ transition at $1386.97 \mathrm{~cm}^{-1}$. In the absence of absolute calibration available on the EXES instrument for our Mars data, we have not converted the continuum radiance map into a brightness temperature map.

Figure 8 shows the maps of the line depths of $\mathrm{H}_{2} \mathrm{O}$ at $1388.5 \mathrm{~cm}^{-1}$ and HDO at $1388.0 \mathrm{~cm}^{-1}$, as observed on March 24, $2016\left(\mathrm{Ls}=127^{\circ}\right)$. The $\mathrm{H}_{2} \mathrm{O}$ and HDO line depth maps show similar behaviors with a distinct enhancement around the north pole, as expected from the EMCD predictions during northern summer (Montmessin et al. 2005). Using our radiative transfer model and measuring the $\mathrm{H}_{2} \mathrm{O} / \mathrm{CO}_{2}$ and $\mathrm{HDO} / \mathrm{CO}_{2}$ line depth ratios (ldr) for different values of the $\mathrm{H}_{2} \mathrm{O}$ and HDO volume mixing ratios (vmr), we converted these line depths into volume mixing ratios of $\mathrm{H}_{2} \mathrm{O}$ and $\mathrm{HDO}$, using the $\mathrm{CO}_{2}$ transition at $1386.97 \mathrm{~cm}^{-1}$ and the following linearity 
EXES- March 24, $2016-\mathrm{Ls}=127^{\circ}$

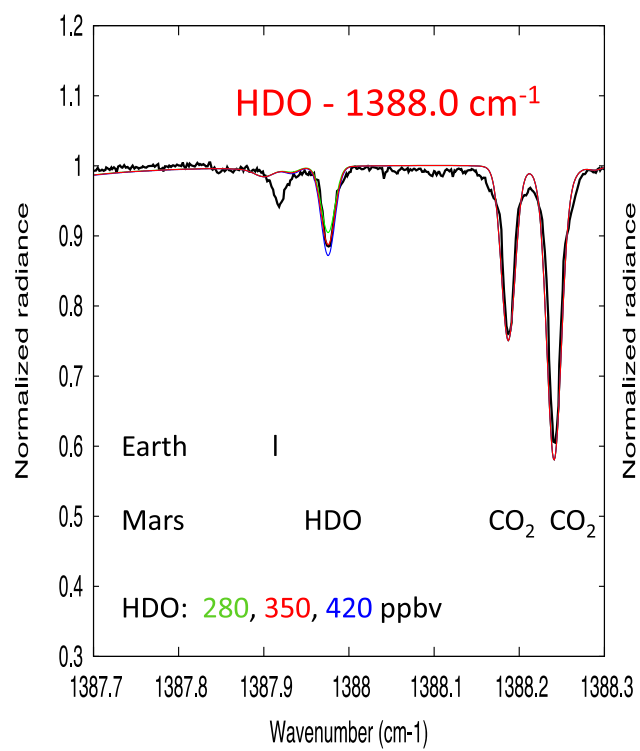

Continuum

$1388.42 \mathrm{~cm}^{-1}$

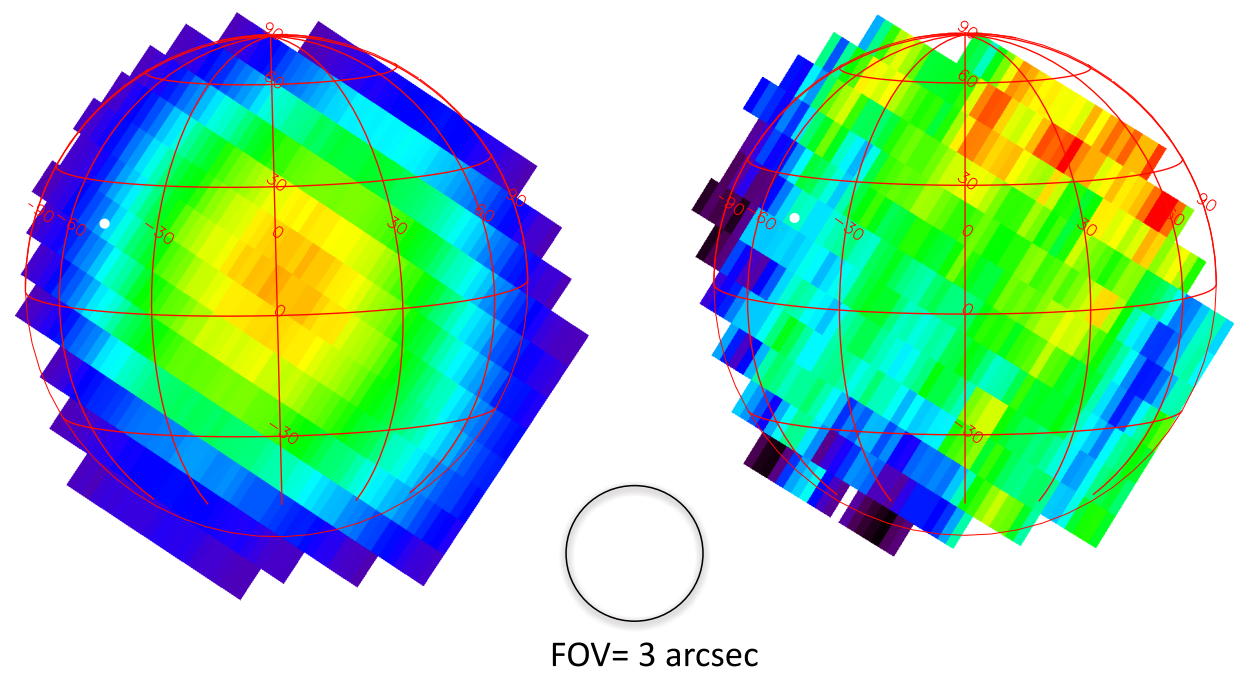

$\mathrm{FOV}=3 \operatorname{arcsec}$

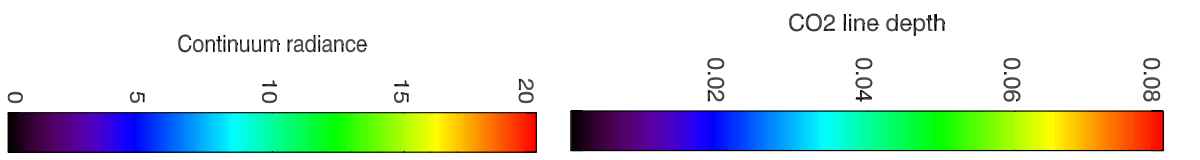

Fig. 6. Thick black line: the EXES diskintegrated spectrum of Mars recorded on March 24, 2016 in two HDO transitions. Left: the $1388.0 \mathrm{~cm}^{-1}$ transition; right: the $1389.1 \mathrm{~cm}^{-1}$ transition. Models: $\mathrm{HDO}=280 \mathrm{ppmv}$ (green), $350 \mathrm{ppbv}$ (red, best fit), 420 ppbv (blue).
Fig. 7. Left: continuum radiance map of the Martian disk recorded at $1388.42 \mathrm{~cm}^{-1}$ on March 24, 2016 $\left(\mathrm{L} s=127^{\circ}\right)$, with EXES. Right: map of the line depth of a weak $\mathrm{CO}_{2}$ transition at $1386.97 \mathrm{~cm}^{-1}$. The white dot corresponds to the position of the subsolar point. The spatial resolution is limited by the pointing accuracy of the SOFIA telescope. The field of view is indicated by a circle at the center of the figure. relationships derived from the best-fit model of the diskintegrated spectrum:

$$
\operatorname{vmr}\left(\mathrm{H}_{2} \mathrm{O}\right)(\mathrm{ppmv})=280.0 / 1.717 \times \operatorname{ldr}\left(\mathrm{H}_{2} \mathrm{O} / \mathrm{CO}_{2}\right),
$$$$
\operatorname{vmr}(\mathrm{HDO})(\mathrm{ppbv})=350.0 / 1.833 \times \operatorname{ldr}\left(\mathrm{HDO} / \mathrm{CO}_{2}\right) \text {. }
$$

The latitudinal trend shown in Fig. 9 is qualitatively consistent with the EMCD predictions for northern summer.

Figure 10 shows the $\mathrm{D} / \mathrm{H}$ ratio on Mars, directly inferred from the $\mathrm{HDO} / \mathrm{H}_{2} \mathrm{O}$ line depth ratio, using the following relationship:

$$
\mathrm{D} / \mathrm{H}=0.5 \times \operatorname{vmr}(\mathrm{HDO}) / \mathrm{vmr}\left(\mathrm{H}_{2} \mathrm{O}\right)
$$

or

$\mathrm{D} / \mathrm{H}($ VSMOW units $)=4.0 / 1.07 \times \operatorname{ldr}\left(\mathrm{HDO} / \mathrm{H}_{2} \mathrm{O}\right)$.

Figure 10 shows the two D/H maps of April 2014 and March 2016 for comparison. The two maps are in good agreement, as expected in view of the similarities in season and longitude ranges for both observing runs. Our map of March 2016 is of lower quality than the earlier one because of the smaller size of the planet and the limited spatial resolution of the SOFIA telescope.

In order to confirm these results, we isolated two areas along the Central Meridian, extending respectively from $45^{\circ} \mathrm{N}$ up to 
$\mathrm{H}_{2} \mathrm{O} 1388.5 \mathrm{~cm}^{-1}$
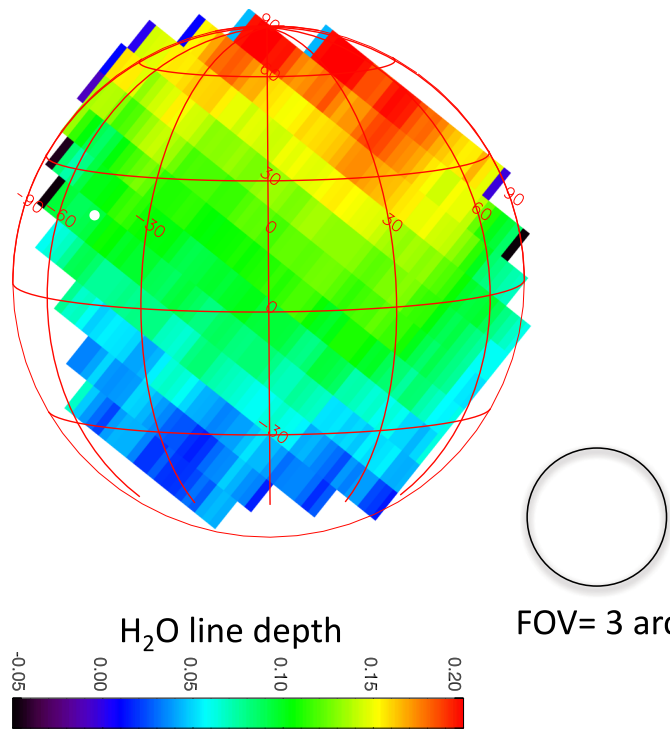

$\mathrm{FOV}=3 \operatorname{arcsec}$

\section{HDO $1388.0 \mathrm{~cm}^{-1}$}
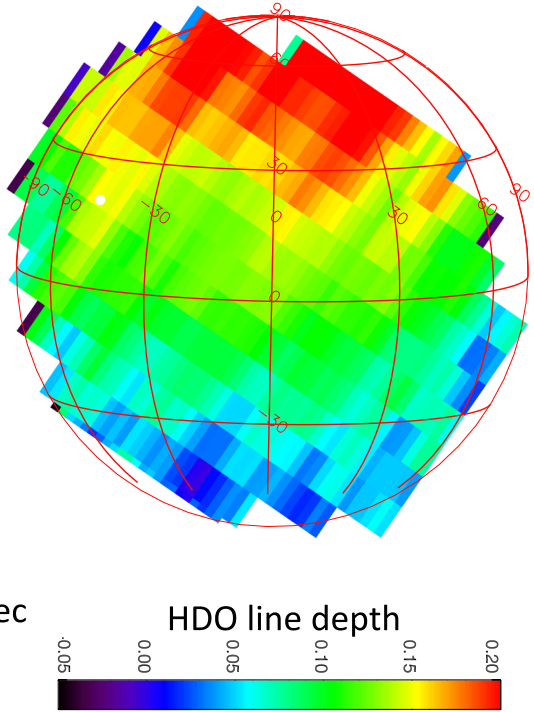

Fig. 8. Maps of the line depths for $\mathrm{H}_{2} \mathrm{O}$ at $1388.5 \mathrm{~cm}^{-1}$ (left) and $\mathrm{HDO}$ at $1388.0 \mathrm{~cm}^{-1}$ (right), recorded with EXES on March 24, $2016\left(\mathrm{~L} s=127^{\circ}\right)$. The white dot corresponds to the position of the subsolar point. The field of view is indicated by a circle at the center of the figure.

\section{$\mathrm{H}_{2} \mathrm{O}-1388.5 \mathrm{~cm}^{-1} \quad \mathrm{HDO}-1388.0 \mathrm{~cm}^{-1}$ $\mathrm{CO}_{2}-1386.97 \mathrm{~cm}^{-1}$}

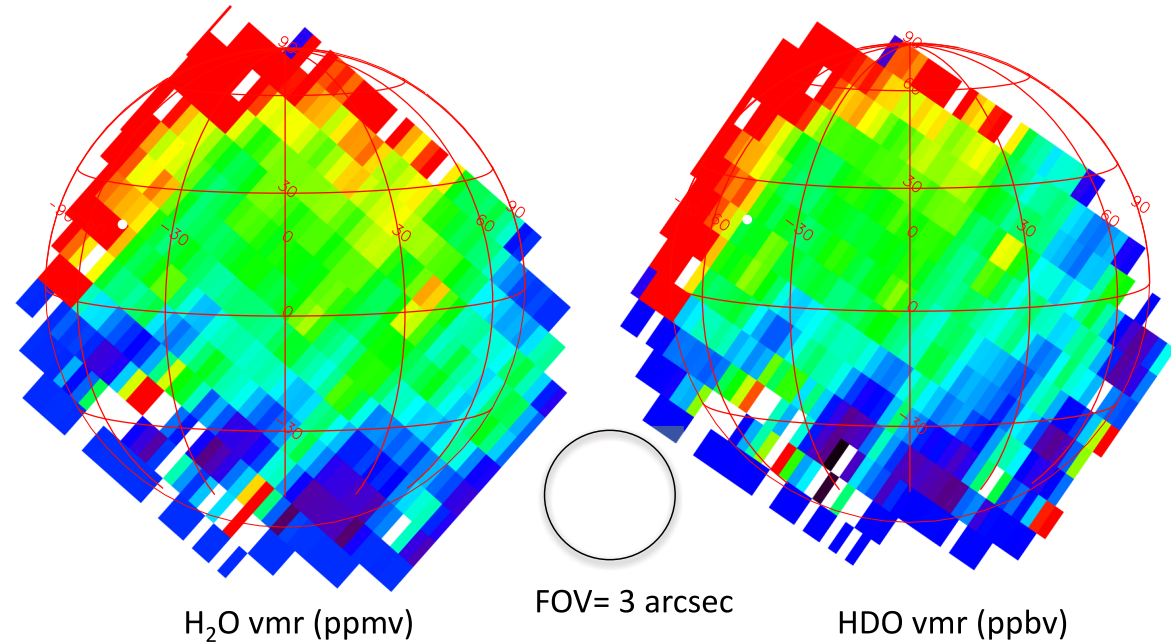

○ $\overrightarrow{8}$ 요

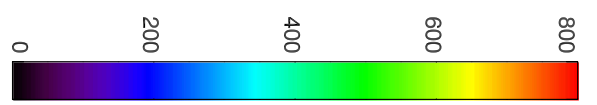

Fig. 9. Maps of the volume mixing ratio of $\mathrm{H}_{2} \mathrm{O}$, derived from the $1388.5 \mathrm{~cm}^{-1}$ transition (left), and the volume mixing ratio of HDO, derived from the $1388.0 \mathrm{~cm}^{-1}$ transition (right), recorded with EXES on March 24, 2016 $\left(\mathrm{L} s=127^{\circ}\right)$. The $\mathrm{CO}_{2}$ transition at $1386.97 \mathrm{~cm}^{-1}$ is used in both cases. The white dot corresponds to the position of the subsolar point. The field of view is indicated by a circle at the center of the figure. the north limb and from $30^{\circ} \mathrm{S}$ down to the south limb. We note that some fluctuations are present in the continuum, probably of instrumental origin. It can be seen that these continuum fluctuations are not visible on disk-integrated spectra, but appear on localized spectra, especially when high airmasses are considered; in these regions, the blurring due to the poor seeing of the SOFIA telescope is most severe. As in our previous analysis, for comparison with the synthetic models, we removed these fluctuations by assuming, for each transition, a straight line between the continuum taken on each side of the transition. We also noticed that continuum fluctuations were stronger toward the high frequency range of the spectra; for this reason, we removed the $1391.0 \mathrm{~cm}^{-1} \mathrm{H}_{2} \mathrm{O}$ line from the analysis of the localized spectra. We thus kept the $1388.5 \mathrm{~cm}^{-1} \mathrm{H}_{2} \mathrm{O}$ line and the two HDO lines, at 1388.0 and $1389.1 \mathrm{~cm}^{-1}$ respectively (Figs. 10 and 11).

To model the synthetic spectra, we adopted atmospheric parameters derived from the EMCD for the corresponding location and season. Figures 11 and 12 show the best fits obtained for the $\mathrm{H}_{2} \mathrm{O}$ and $\mathrm{HDO}$ mixing ratios in the northern and southern region, respectively. The following mixing ratios are inferred:

Disk-integrated spectrum: $\mathrm{H}_{2} \mathrm{O}=280(+37,-27)$ ppmv, $\mathrm{HDO}=350( \pm 47) \mathrm{ppbv}, \mathrm{D} / \mathrm{H}=4.0(+0.8,-0.6) \times \mathrm{VSMOW}$ ( $1 \sigma$ error bars); 


\section{$\mathrm{D} / \mathrm{H}$}

April 8, $2014-\mathrm{Ls}=113^{\circ}$

Mars diameter $=15$ arcsec

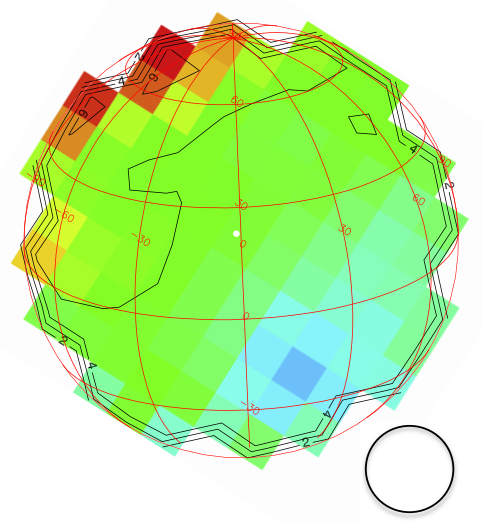

$\mathrm{D} / \mathrm{H}$ (x VSMOW)

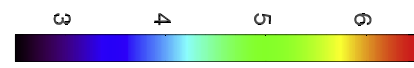

$\mathrm{FOV}=3$ arcsec
March 24, $2016-\mathrm{Ls}=127^{\circ}$

Mars diameter $=11$ arcsec

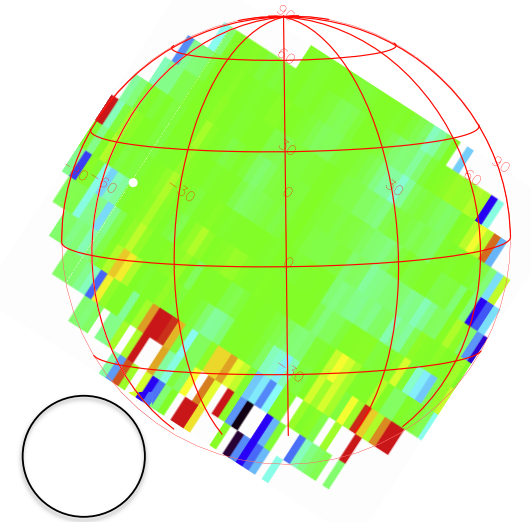

$\mathrm{D} / \mathrm{H}$ (x VSMOW)

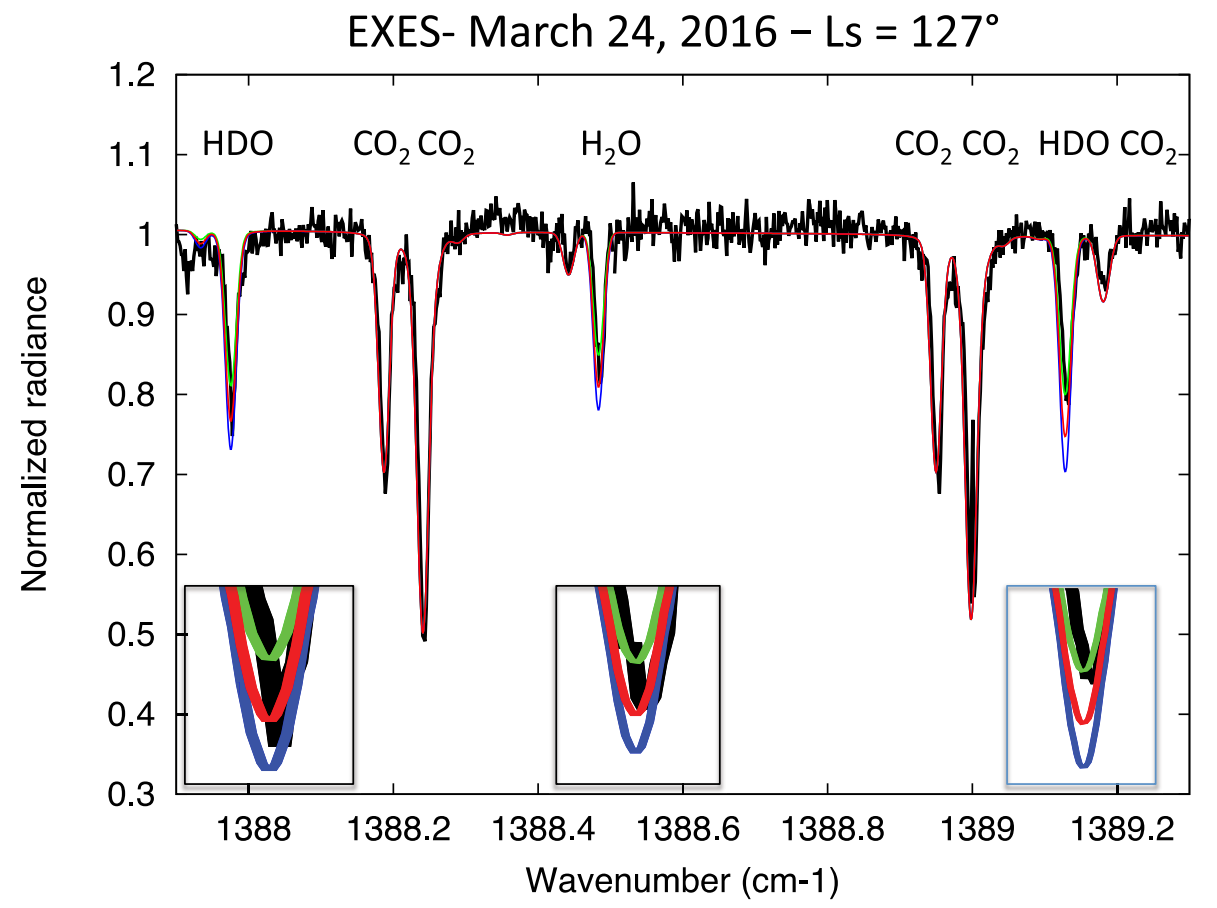

Fig. 10. Maps of the $\mathrm{D} / \mathrm{H}$ ratio on Mars, inferred from the EXES data recorded on April 8, $2014\left(\mathrm{~L} s=113^{\circ}\right.$, left $)$, and March 24, $2016\left(\mathrm{Ls}=127^{\circ}\right.$, right $)$. The white dot corresponds to the position of the subsolar point. For each observation, the field of view is indicated by a circle at the center of the figure.

Fig. 11. Black line: spectrum of Mars recorded on March 24, 2016, in the northern region between 1387.9 and $1389.3 \mathrm{~cm}^{-1}$. Models: $\mathrm{H}_{2} \mathrm{O}=250$ ppmv, $\mathrm{HDO}=400 \mathrm{ppbv}$ (green); $\mathrm{H}_{2} \mathrm{O}=375 \mathrm{ppmv}, \mathrm{HDO}=550 \mathrm{ppbv}$ (red, best fit); $\mathrm{H}_{2} \mathrm{O}=500$ ppmv, $\mathrm{HDO}=$ 700 ppbv (blue). The surface pressure is 6 $\mathrm{mb}$ and the surface brightness temperature is $255 \mathrm{~K}$. The temperature profile is the same as that used for the integrated spectrum (see Sect. 2.2). The airmass is 2.0 .

Northern region: $\mathrm{H}_{2} \mathrm{O}=375( \pm 125)$ ppmv, $\mathrm{HDO}=550$ $( \pm 100) \mathrm{ppbv}, \mathrm{D} / \mathrm{H}=4.7(+2.4,-1.3) \times \mathrm{VSMOW}(1 \sigma$ error bars $)$;

Southern region: $\mathrm{H}_{2} \mathrm{O}=125(+125,-67)$ ppmv, $\mathrm{HDO}=150$ $(+100,-50)$ ppbv, $\mathrm{D} / \mathrm{H}=3.8(+2.8,-2.0) \times$ VSMOW $(1 \sigma$ error bars).

We note that in the southern region, the $\mathrm{H}_{2} \mathrm{O}$ and $\mathrm{HDO}$ line depths are too small for a reliable value of $\mathrm{D} / \mathrm{H}$ to be determined. We note also that, surprisingly, the two HDO transitions do not fit the same HDO volume mixing ratio; the observed $1389.1 \mathrm{~cm}^{-1}$ transition appears slightly weaker than the $1388.0 \mathrm{~cm}^{-1}$ transition compared with the EMCD predictions. We have no explanation for this discrepancy, which does not appear on the other EXES spectra.

\subsection{The January 2017 observations}

Figure 13 shows the geometry of the observation performed on January 24, 2017. A first (interrupted) scan was recorded at 0:50 UT, along the disk center from north to south, with a polar angle of $139^{\circ}$. Then, six successive scans of about 5 minutes each were recorded between 0:55 and 01:30 UT, with a shift of $\pm 1 \operatorname{arcsec}$ with respect to the disk center.

Figure 14 shows the integrated radiance over the 1383-1391 $\mathrm{cm}^{-1}$ for each of the seven scans, as a function of the pixel number. The latitude coverage of the observations ranges from about $45^{\circ} \mathrm{N}$ to $90^{\circ} \mathrm{S}$. The longitude coverage ranges from $270^{\circ} \mathrm{W}$ to $330^{\circ} \mathrm{W}$. However, there is a considerable uncertainty in the location of each scan, due to the 3 arcsec spatial 


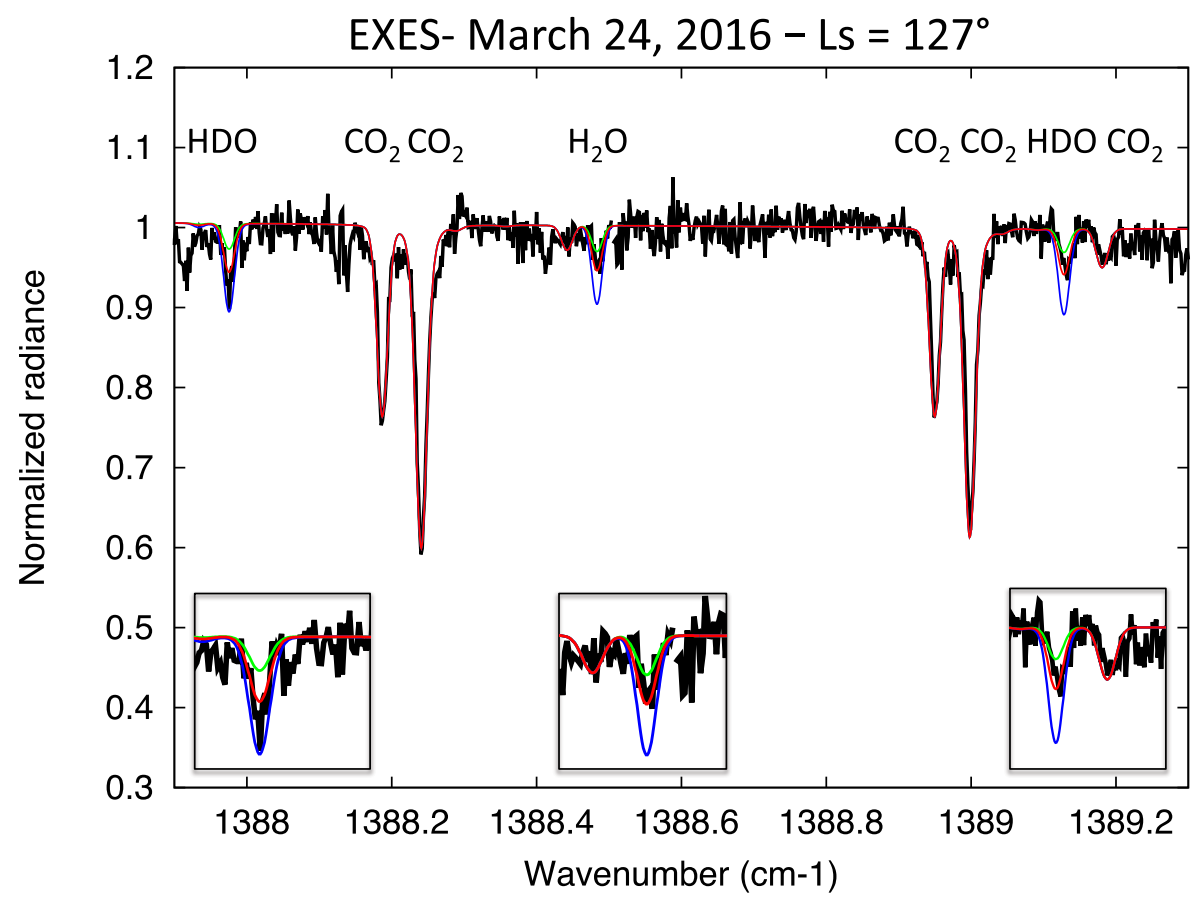

Fig. 12. Black line: spectrum of Mars recorded on March 24, 2016, in the southern region between 1387.9 and $1389.3 \mathrm{~cm}^{-1}$. Models: $\mathrm{H}_{2} \mathrm{O}=67$ ppmv, $\mathrm{HDO}=75 \mathrm{ppbv}$ (green); $\mathrm{H}_{2} \mathrm{O}=125 \mathrm{ppmv}, \mathrm{HDO}=150 \mathrm{ppbv}$ (red, best fit); $\mathrm{H}_{2} \mathrm{O}=250 \mathrm{ppmv}, \mathrm{HDO}=300$ ppbv (blue). The surface pressure is $5 \mathrm{mb}$ and the surface brightness temperature is $235 \mathrm{~K}$. The temperature profile is the same as that used for the integrated spectrum (see Sect. 2.2). The airmass is 2.0.

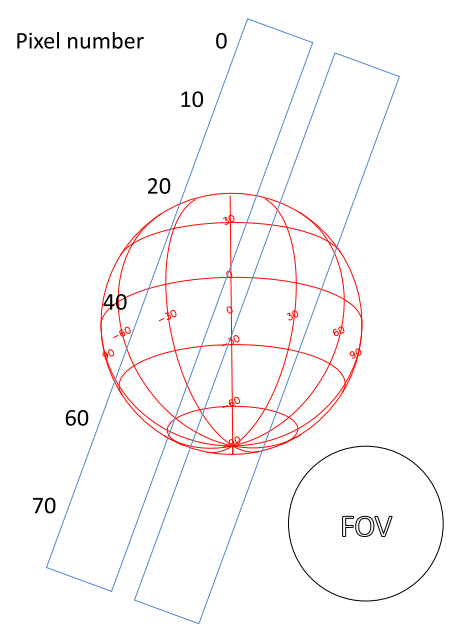

Fig. 13. Geometry of the EXES observation of January 24, 2017. The diameter of Mars is 5.2 arcsec. The longitude and latitude of the sub-Earth point are $357^{\circ} \mathrm{W}$ and $26^{\circ} \mathrm{S}$, respectively. The longitude and latitude of the subsolar point are $321^{\circ} \mathrm{W}$ and $21^{\circ} \mathrm{S}$, respectively. The two positions of the slit, at an equal distance from the disk center, are separated by 2 arcsec. The field of view is indicated on the right side of the figure.

resolution of the SOFIA telescope. Since the diameter of Mars is only 5.2 arcsec, this limitation converts into an uncertainty of about $60^{\circ}$ in longitude for each scan. The latitude coverage can be determined by the shape of the continuum radiance that peaks near the latitude of the sub-Earth point at $25^{\circ} \mathrm{S}$. Figure 14 shows that all scans show a comparable value of the maximum radiance around pixel 40 (presumably $25^{\circ} \mathrm{S}$ latitude). This result is surprising, as we would have expected a higher radiance near the subsolar point at a longitude of about $330^{\circ} \mathrm{W}$ (on the right side of the figure). We interpret this result as being due to the large uncertainty in the longitude location of the scans.

We analyzed each scan individually, and we performed in each case the analysis of the $\mathrm{H}_{2} \mathrm{O}$ and $\mathrm{HDO}$ mixing ratios. We

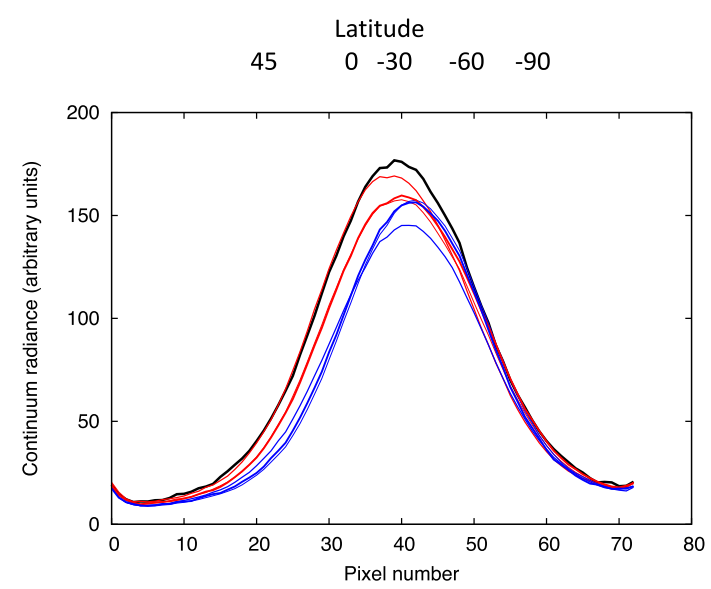

Fig. 14. EXES radiance, integrated over the $1383-1391 \mathrm{~cm}^{-1}$ range, as a function of the pixel number along the slit. Black: first scan (interrupted) recorded along the disk center $\left(357^{\circ} \mathrm{W}\right.$ longitude). Red: "left" scans (centered around $15^{\circ} \mathrm{W}$ longitude). Blue: "right" scans (centered around $345^{\circ} \mathrm{W}$ longitude). There is considerable uncertainty on the position of the slit with respect to the Martian disk.

find no significant difference between the results obtained in the "left" scans $\left(30^{\circ} \mathrm{W}\right.$ longitude) and the "right" scans $\left(330^{\circ} \mathrm{W}\right.$ longitude). In view of the considerable uncertainty in the longitude determination, we summed all the scans together to perform an analysis of $\mathrm{H}_{2} \mathrm{O}, \mathrm{HDO}$, and $\mathrm{D} / \mathrm{H}$ as a function of latitude only.

We first consider the slit-integrated spectrum. Figure 15 shows the two weak transitions of $\mathrm{H}_{2} \mathrm{O}$ at 1388.5 and $1391.0 \mathrm{~cm}^{-1}$ used for our analysis. The best fit is obtained for a $\mathrm{H}_{2} \mathrm{O}$ volume mixing ratio of $250 \pm 34$ ppmv. Figure 16 shows the two HDO transitions at 1388.0 and $1389.1 \mathrm{~cm}^{-1}$. We derive a HDO mixing ratio of $350 \pm 47$ ppbv. Taking into account the two lines of each species, we derive for the January 2017 data a $\mathrm{D} / \mathrm{H}$ ratio of $4.5(+0.7,-0.6) \times \mathrm{VSMOW}$. We note that, as in the case of the March 2016 data, the Martian lines are well 
EXES- January 24, $2017-\mathrm{Ls}=304^{\circ}$
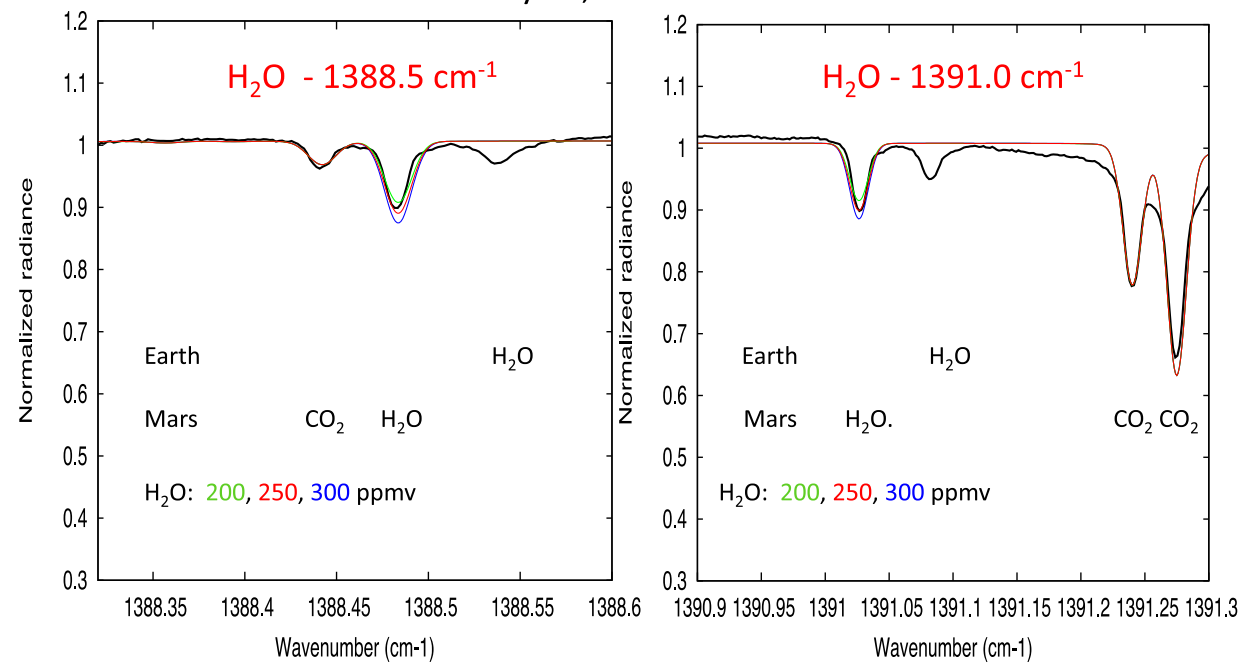

EXES- January 24, $2017-\mathrm{Ls}=304^{\circ}$
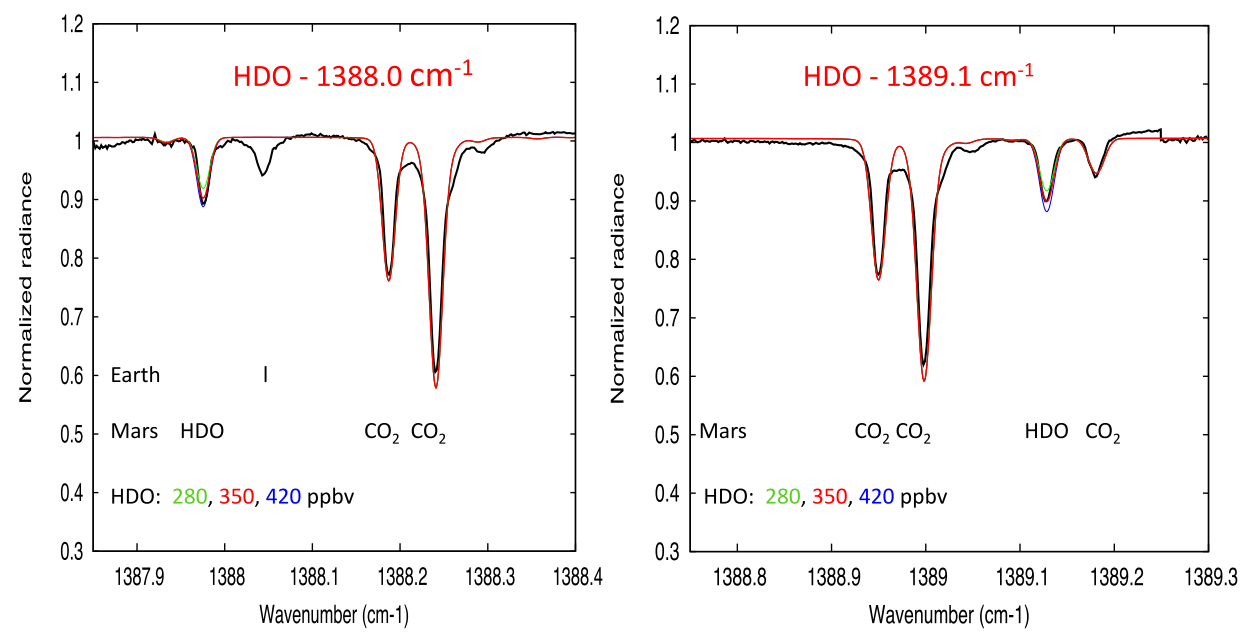

Fig. 15. Thick black line: EXES slitintegrated spectrum of Mars recorded on January 24,2017 , in two weak $\mathrm{H}_{2} \mathrm{O}$ transitions. Left: $1388.5 \mathrm{~cm}^{-1}$ transition; right: $1391.0 \mathrm{~cm}^{-1}$ transition. Models: $\mathrm{H}_{2} \mathrm{O}=240$ ppmv (green), 280 ppmv (red, best fit), 335 ppmv (blue).
Fig. 16. Thick black line: EXES slitintegrated spectrum of Mars recorded on January 24, 2017, in two weak HDO transitions. Left: $1388.0 \mathrm{~cm}^{-1}$ transition; right: $1389.1 \mathrm{~cm}^{-1}$ transition. Models: $\mathrm{HDO}=280 \mathrm{ppmv}$ (green), $350 \mathrm{ppbv}$ (red, best fit), 420 ppbv (blue).

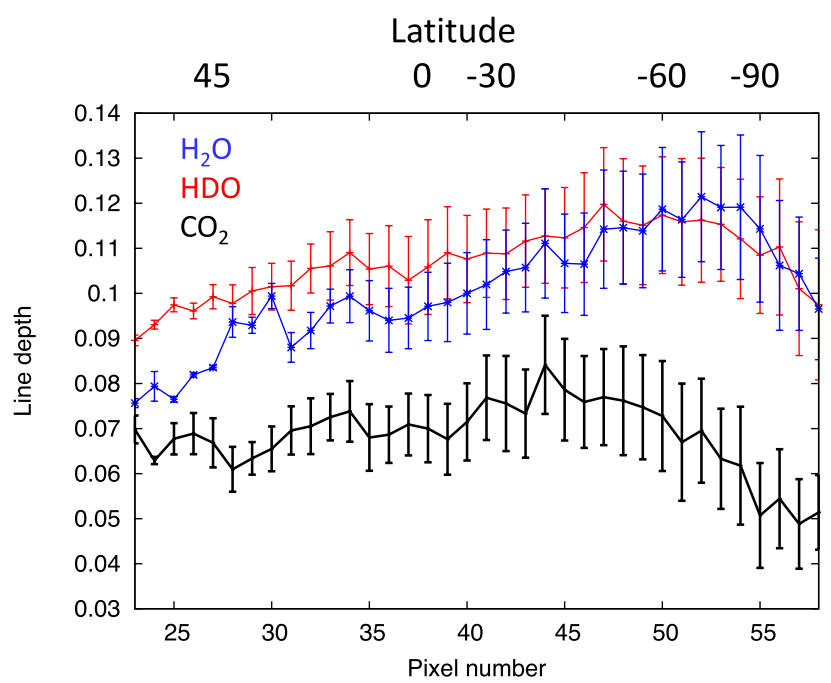

Fig. 17. Line depths of the $\mathrm{CO}_{2}\left(1389.2 \mathrm{~cm}^{-1}\right.$, black), $\mathrm{H}_{2} \mathrm{O}$ (1388.5 $\mathrm{cm}^{-1}$, blue), and HDO (1388.0 and $1389.1 \mathrm{~cm}^{-1}$, mean value, red) as a function of latitude, integrated over the six scans. Data are from January 24, 2017.

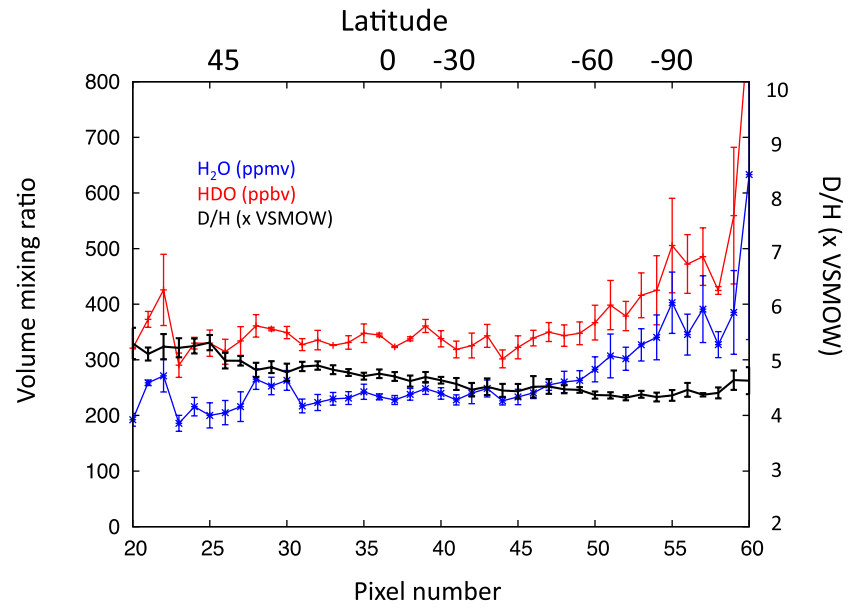

Fig. 18. Volume mixing ratios of $\mathrm{H}_{2} \mathrm{O}$ (in ppmv, blue) and $\mathrm{HDO}$ (in ppbv, red), using the line depth ratios of $\mathrm{H}_{2} \mathrm{O} / \mathrm{CO}_{2}$ (blue) and $\mathrm{HDO} / \mathrm{CO}_{2}$ (red) for the transitions shown in Fig. 17. Black: the D/H ratio inferred from the $\mathrm{HDO} / \mathrm{H}_{2} \mathrm{O}$ line depth ratio. The data are shown as a function of latitude, integrated over the six scans. Data are from January 24 , 2017. 


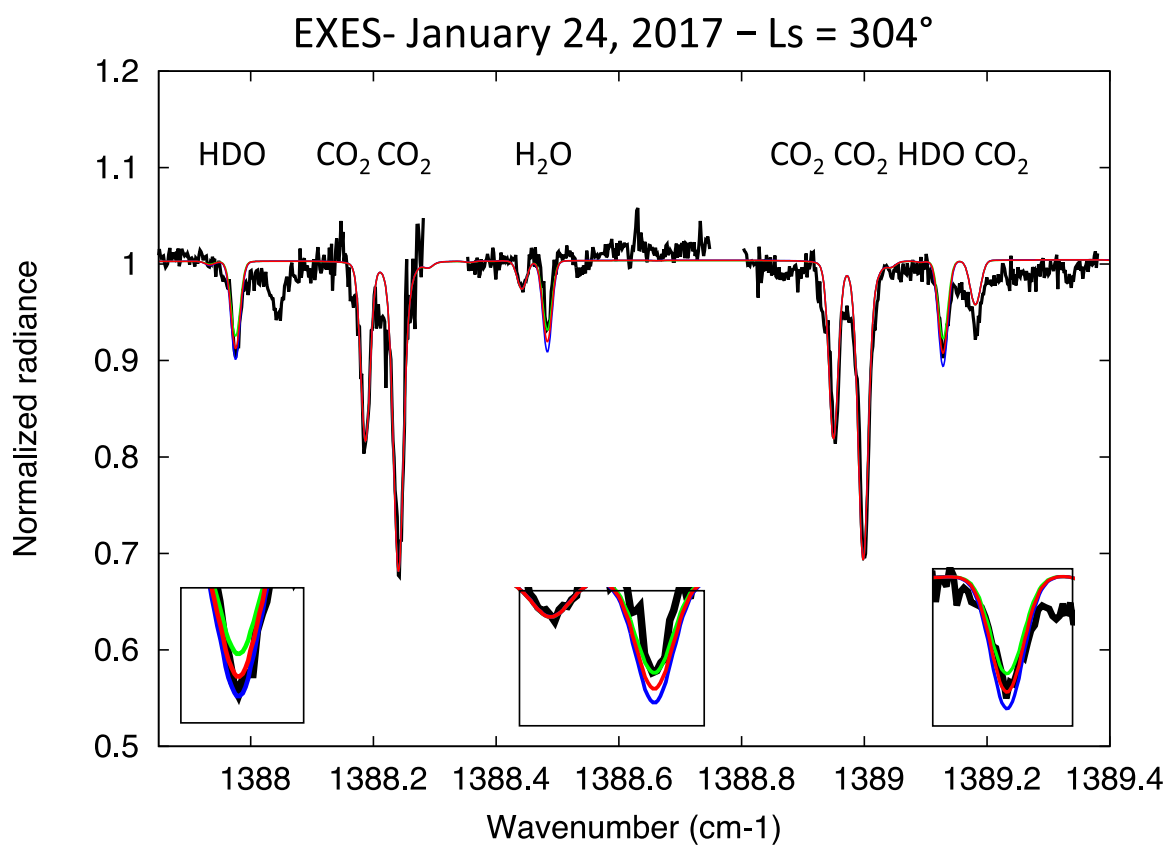

Fig. 19. Black line: spectrum of Mars recorded on January 24, 2017, in the northern region between 1387.9 and $1389.4 \mathrm{~cm}^{-1}$, recorded on January 24, 2017. Models: $\mathrm{H}_{2} \mathrm{O}$ $=200$ ppmv, $\mathrm{HDO}=280 \mathrm{ppbv}($ green $) ; \mathrm{H}_{2} \mathrm{O}$ $=250 \mathrm{ppmv}, \mathrm{HDO}=350 \mathrm{ppbv}$ (red, best fit); $\mathrm{H}_{2} \mathrm{O}=300$ ppmv, $\mathrm{HDO}=420$ ppbv (blue). The surface pressure is $7.5 \mathrm{mb}$ and the surface brightness temperature is $212 \mathrm{~K}$. The temperatures at altitudes of $0,10,20$, and $40 \mathrm{~km}$ are $205,202,200$, and $185 \mathrm{~K}$, respectively. The airmass is 2.0 . separated from the terrestrial counterparts, so that there is no contamination from terrestrial atmospheric opacity.

We now consider the variation in the $\mathrm{H}_{2} \mathrm{O}$ and $\mathrm{HDO}$ volume mixing ratios as a function of latitude. After trying different sets of lines, we selected the $\mathrm{CO}_{2}$ transition at $1389.2 \mathrm{~cm}^{-1}$, the $\mathrm{H}_{2} \mathrm{O}$ line at $1388.5 \mathrm{~cm}^{-1}$, and the two HDO lines at 1388.0 and $1389.1 \mathrm{~cm}^{-1}$ which give the best signal-to-noise ratios for the line depth ratios. Figure 17 shows the line depths of the $\mathrm{CO}_{2}$ transition, the $\mathrm{H}_{2} \mathrm{O}$ transition, and the mean value of the two HDO transitions. These data are summed over the six scans and the error bars are calculated from the dispersion of these values between the scans. We note that they do not correspond to the instrumental noise, but they reflect true variations in the $\mathrm{CO}_{2}, \mathrm{H}_{2} \mathrm{O}$, and $\mathrm{HDO}$ line depths as different locations of the planet are observed along the different scans.

Figure 18 shows the $\mathrm{H}_{2} \mathrm{O}$ and $\mathrm{HDO}$ volume mixing ratios and the $\mathrm{D} / \mathrm{H}$ ratio inferred from the line depths shown in Fig. 16, determined using the best fits shown in Figs. 15 and 16 for the slit-integrated spectra. The following relationships are used:

$$
\begin{aligned}
& \operatorname{vmr}\left(\mathrm{H}_{2} \mathrm{O}\right)(\mathrm{ppmv})=250.0 / 1.7 \times \operatorname{ldr}\left(\mathrm{H}_{2} \mathrm{O} / \mathrm{CO}_{2}\right), \\
& \operatorname{vmr}(\mathrm{HDO})(\mathrm{ppbv})=350.0 / 1.53 \times \operatorname{ldr}\left(\mathrm{HDO} / \mathrm{CO}_{2}\right), \\
& \text { D/H }(\text { VSMOW units })=4.5 / 1.11 \times \operatorname{ldr}\left(\mathrm{HDO} / \mathrm{H}_{2} \mathrm{O}\right) .
\end{aligned}
$$

As in the case of Fig. 17, the error bars are calculated from the dispersion of the six scans. They are significantly lower than in Fig. 17, which illustrates that the $\mathrm{H}_{2} \mathrm{O}$ and $\mathrm{HDO}$ mixing ratios, and even more $\mathrm{D} / \mathrm{H}$, are the same for all scans and show little dependence upon topographic variations. It must be noted that these error bars do not include uncertainties associated with the radiative transfer model. They are thus significantly smaller than the final error bars inferred from the spectral fittings (see Figs. 19 and 20).

It is interesting to note that the $\mathrm{D} / \mathrm{H}$ ratio shows an increasing trend from southern toward northern latitudes, while - as predicted by the EMCD during southern summer $\left(\mathrm{L} s=304^{\circ}\right)-$ the $\mathrm{H}_{2} \mathrm{O}$ and $\mathrm{HDO}$ volume mixing ratios both show maximum values near high southern latitudes. This trend is not predicted by global models of the $\mathrm{D} / \mathrm{H}$ distribution as a function of latitude and season (Montmessin et al. 2005). We have checked that this trend is observed individually on all six scans, and also using both HDO transitions individually.

In order to check the consistency of our results, and in particular the evolution of $\mathrm{D} / \mathrm{H}$ with latitude, we have isolated two areas, in the northern part (pixels 20 to $25,30^{\circ} \mathrm{N}-45^{\circ} \mathrm{N}$ latitudes) and the southern part (pixels 55 to $60,60^{\circ} \mathrm{S}-90^{\circ} \mathrm{S}$ latitudes) of the slit. Figures 19 and 20 show the corresponding EXES spectra between 1387.8 and $1389.4 \mathrm{~cm}^{-1}$ (summed over the six scans), compared to synthetic models. As in the case of the 2016 data, in both cases we used the atmospheric parameters inferred from the EMCD for the corresponding location and season (Forget et al. 1999). In the case of the northern area (Fig. 19), the $\mathrm{CO}_{2}$ lines are significantly weaker than in the slit-integrated spectrum, which requires a thermal profile close to isothermal, as also predicted by the EMCD. Our results are summarized below:

Disk-integrated spectrum: $\mathrm{H}_{2} \mathrm{O}=250( \pm 34)$ ppmv, $\mathrm{HDO}=$ $350( \pm 47) \mathrm{ppbv}, \mathrm{D} / \mathrm{H}=4.5(+0.7,-0.6) \times \mathrm{VSMOW}(1 \sigma$ error bars);

Northern region: $\mathrm{H}_{2} \mathrm{O}=250( \pm 50)$ ppmv, $\mathrm{HDO}=350( \pm 47)$ ppbv, D/H = $4.5(+1.3,-0.9) \times$ VSMOW $(1 \sigma$ error bars $)$;

Southern region: $\mathrm{H}_{2} \mathrm{O}=350( \pm 50)$ ppmv, $\mathrm{HDO}=490( \pm 47)$ ppbv, $\mathrm{D} / \mathrm{H}=4.5(+0.9,-0.7) \times$ VSMOW $(1 \sigma$ error bars $)$.

In the case of the northern region, we infer the same results as in the case of the slit-integrated spectrum. In the case of the southern area, the best-fit values of the $\mathrm{H}_{2} \mathrm{O}$ and $\mathrm{HDO}$ vmrs are significantly higher; both conclusions are consistent with the variations shown in Fig. 18. It can be seen that the error bars on $\mathrm{D} / \mathrm{H}$ are too large for us to confirm the reality of a variation of the $\mathrm{D} / \mathrm{H}$ ratio over latitude.

\section{Discussion}

Our result of March 2016 can first be compared to our earlier EXES observation of April 2014, which was obtained in a 
EXES- January $24,2017-$ Ls $=304^{\circ}$

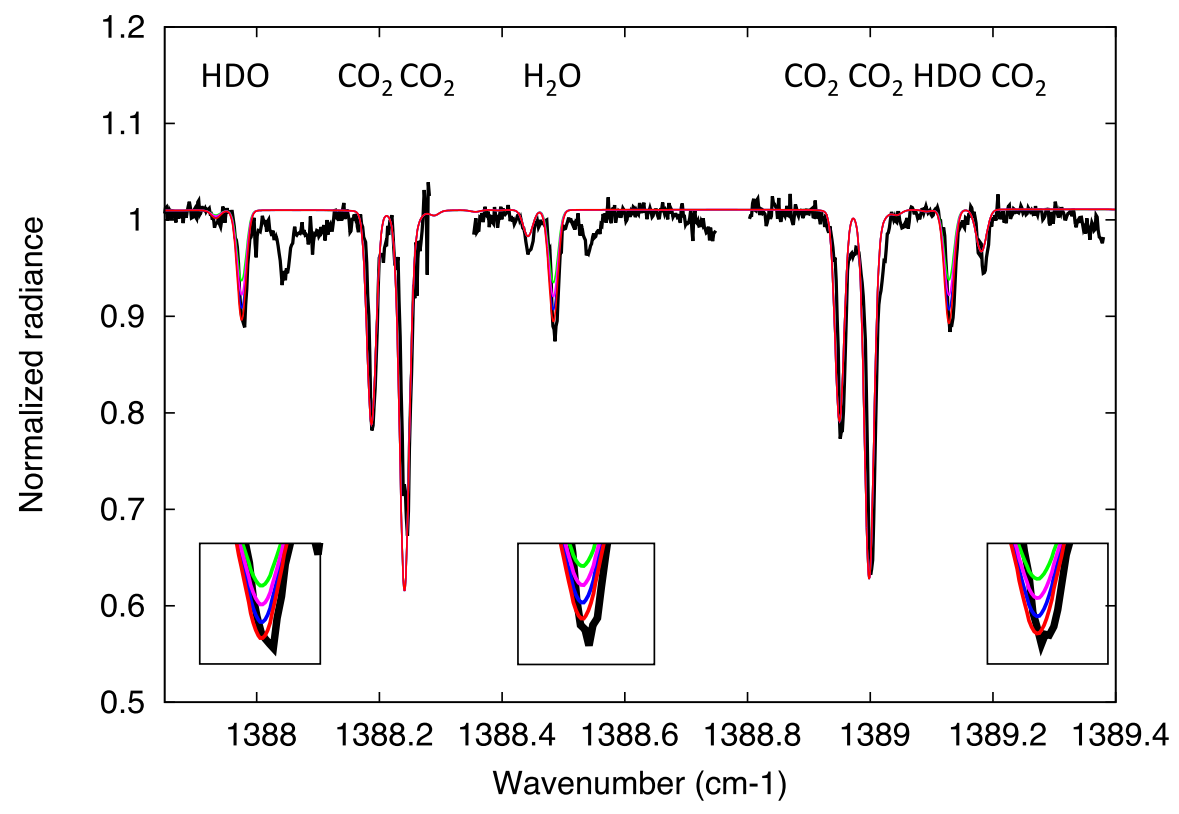

Fig. 20. Black line: spectrum of Mars recorded on January 24, 2017, in the southern region between 1387.9 and $1389.4 \mathrm{~cm}^{-1}$ ). Models: $\mathrm{H}_{2} \mathrm{O}=200$ ppmv, $\mathrm{HDO}=280 \mathrm{ppbv}$ (green); $\mathrm{H}_{2} \mathrm{O}=250$ ppmv, $\mathrm{HDO}=350$ ppbv (purple); $\mathrm{H}_{2} \mathrm{O}=350$ ppmv, HDO $=420$ ppbv (blue); $\mathrm{H}_{2} \mathrm{O}=350$ ppmv, $\mathrm{HDO}=490 \mathrm{ppbv}$ (red, best fit). The surface pressure is $5.0 \mathrm{mb}$ and the surface temperature is $260 \mathrm{~K}$. The temperatures at altitudes of $0,10,20$, and $40 \mathrm{~km}$ are 235 , 215,190 , and $165 \mathrm{~K}$, respectively. The airmass is 2.0 .

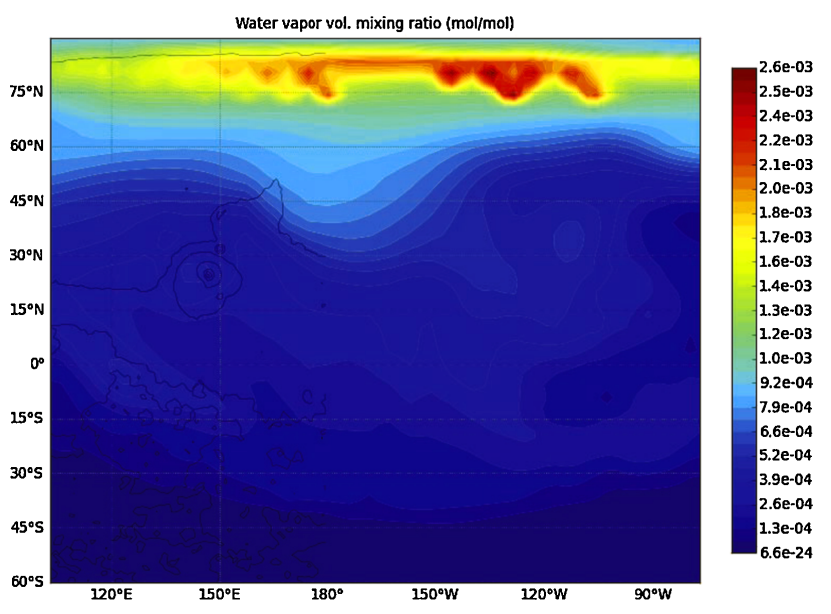

Fig. 21. Spatial distribution of the $\mathrm{H}_{2} \mathrm{O}$ mixing ratio on Mars for $\mathrm{L} s=127^{\circ}$ and the geometry of the EXES observation of March 2016, as derived from the EMCD.

comparable season (early northern summer) on similar longitude and latitude ranges. The $\mathrm{H}_{2} \mathrm{O}$ and $\mathrm{HDO}$ abundances and their spatial distributions over the disk are in good agreement for both datasets, as are their disk-averaged values. In both cases, the $\mathrm{H}_{2} \mathrm{O}$ and $\mathrm{HDO}$ abundances indicate a clear maximum at high northern latitude, as expected during northern summer. Figure 21 shows the expected $\mathrm{H}_{2} \mathrm{O}$ mixing ratio for $\mathrm{L} s=127^{\circ}$ and the geometry corresponding to our observations of March 2016, as predicted by the EMCD. The agreement is satisfactory, except at the north pole where the EMCD predicts a very high water content; this discrepancy has been pointed out previously (Encrenaz et al. 2015, 2016). Our disk-averaged D/H value of March 2016 is also consistent with our earlier value $\left[\mathrm{D} / \mathrm{H}=4.4(+1.1,-0.6) \times \mathrm{VSMOW}, \mathrm{L} s=113^{\circ}\right]$, within the range of uncertainty. Figures 11 and 12 seem to indicate a slight increase in $\mathrm{D} / \mathrm{H}$ toward northern latitudes, although this effect is not clearly visible in Fig. 10. The absence of strong latitudinal variation in $\mathrm{D} / \mathrm{H}$ is also consistent with the EMCD predictions for $\mathrm{L} s=127^{\circ}$ (Montmessin et al. 2005).

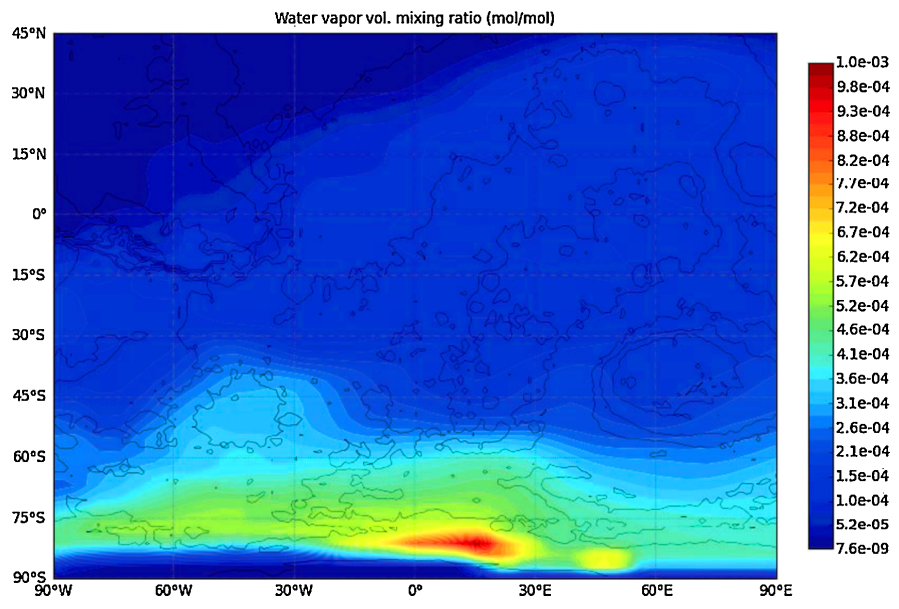

Fig. 22. Spatial distribution of the $\mathrm{H}_{2} \mathrm{O}$ mixing ratio on Mars for $\mathrm{L} s=$ $304^{\circ}$ and the geometry of the EXES observation of January 2017, as derived from the EMCD.

In the case of the January 2017 run, the disk of Mars is observed under opposite conditions, both for the season (southern summer) and for the longitude and latitude ranges. The $\mathrm{H}_{2} \mathrm{O}$ and $\mathrm{HDO}$ volume mixing ratios indicate a clear maximum toward high southern latitudes, as expected from the EMCD (Fig. 22). It is interesting to note that the slit-integrated value (which actually corresponds to a longitude range probably as large as $90^{\circ}$ in view of the pointing uncertainty) is very close to our value of April 2014. This result is also consistent with the EMCD predictions of Montmessin et al. (2005). However, we do not observe an enhancement of $\mathrm{D} / \mathrm{H}$ at high southern latitudes, as expected from the models. In contrast, the variations of $\mathrm{D} / \mathrm{H}$ with latitude instead indicate an opposite trend; however, we caution the reader that it is a tentative conclusion in view of the large uncertainty in our results.

Our globally averaged results from the two datasets are also in good overall agreement with the mean $\mathrm{D} / \mathrm{H}$ mixing ratios derived by Aoki et al. (2015) who found $\mathrm{D} / \mathrm{H}=4.1$ $( \pm 1.4) \times \mathrm{VSMOW}$ for $\mathrm{L} s=52^{\circ}$ and $4.4( \pm 1.0) \times \mathrm{VSMOW}$ 
for $\mathrm{L} s=96^{\circ}$. They are within the range of the $\mathrm{D} / \mathrm{H}$ values inferred by Villanueva et al. (2015) for $\mathrm{L} s=80^{\circ}, 83^{\circ}$, and $335^{\circ}$. They are also consistent with the $\mathrm{D} / \mathrm{H}$ global value obtained by Krasnopolsky (2015) who inferred, from data obtained during six different seasons between 2007 and 2014, a mean D/H mixing ratio of $4.6( \pm 0.7) \times$ VSMOW.

In summary, the main conclusions of the present study are that (1) we do not see strong variations of the disk-integrated value of $\mathrm{D} / \mathrm{H}$ as a function of season, and (2) we do not see strong, large-scale variations of $\mathrm{D} / \mathrm{H}$ as a function of latitude, in contrast with the results reported by Villanueva et al. (2015). We note, however, that this comparison is limited by the poor spatial resolution of our observations. In the future, we plan to complete this program by observing Mars with EXES during other seasons and with a larger angular diameter.

Acknowledgements. This article is based on observations made with the NASA/DLR Stratospheric Observatory for Infrared Astronomy (SOFIA). SOFIA is jointly operated by the Universities Space Research Association, Inc. (USRA), under NASA contract NAS2-97001, and the Deutsches SOFIA Institut (DSI) under DLR contract 50 OK 0901 to the University of Stuttgart. Financial support for this work was provided by NASA. We wish to thank the SOFIA and EXES staff for the support of EXES observations. T.K.G. acknowledges support of NASA Grant NNX14AG34G. T.E. and B.B. acknowledge support from CNRS and Programme National de Planétologie. T.F. acknowledges support from UPMC. T.E. acknowledges support from Jet Propulsion Laboratory as a Distinguished Visiting Scientist.

\section{References}

Aoki, S., Nakagawa, H., Sagawa, H., et al. 2015, Icarus, 260, 7 Bjoraker, G. L., Mumma, M. J., \& Larson, H. P. 1989, BAAS, 21, 991 Encrenaz, T., Lellouch, E., Paubert, G., et al. 2001, Planet. Space Sci., 49, 731 Encrenaz, T., Bézard, B., Greathouse, T. K., et al. 2004, Icarus, 170, 424 Encrenaz, T., Greathouse, T. K., Lefèvre, F., et al. 2015, A\&A, 578, A127 Encrenaz, T., DeWitt, C., Richter, M. J., et al. 2016, A\&A, 586, A62

Forget, F., Hourdin, F., Fournier, R., et al. 1999, J. Geophys. Res., 104, 24155 Fouchet, T., \& Lellouch, E. 2000, Icarus, 144, 114

Greenwood, J. P., Itoh, S., Sakamoto, N., et al. 2008, Geophys. Res. Lett., 35, 5203

Jacquinet-Husson, N., Scott, N., Chedin, A., et al. 2008, J. Quant. Spectr. Rad. Transf., 109, 1043

Jimenez, C., Gulkis, S., Beaudin, G., et al. 2013, Planet. Space Sci., 82, 99

Krasnopolsky, V. A. 2015, Icarus, 257, 377

Krasnopolsky, V. A., Bjoraker, G. L., Mumma, M. J., \& Jenning, D. E. 1997, J. Geophys. Res., 102, 6525

Lacy, J. H., Richter, M. J., Greathouse, T. K., et al. 2002, PASP, 114, 153

Mahaffy, P. R., Webster, C. R., Stern, J. C., et al. 2015, Science, 347, 412

Merlivat, L., \& Nief, G. 1967, Tellus, 19, 122

Montmessin, F., Fouchet, T., \& Forget, F. 2005, J. Geophys. Res., 110, E03006

Novak, R. E., Mumma, M. J., \& Villanueva, G. I. 2011, Planet. Space Sci., 59, 163

Owen, T., Maillard, J.-P., de Bergh, C., \& Lutz, B. L. 1988, Science, 240, 1767

Richter, M. J., Ennico, K. A., Mc Kelvey, M. E., \& Seifhart, A. 2010, in Proc. SPIE, 7735 "Ground-based and Airborne Instrumentation for Astronomy III”, San Diego, CA, USA, June 2010, eds. I. S. McLean, S. Ramsay, \& H. Takami

Usui, H., Alexander, C. M. O. D., Wang, J. et al. 2012, Earth Planet. Sci. Lett., 357,119

Villanueva, G. L., Mumma, M. J., Novak, R. E., et al. 2015, Science, 348, 218 